\title{
LA RECUPERACIÓN \\ DE FRÉDÉRIC LE PLAY ${ }^{1}$
}

\author{
Jesús M. ${ }^{a}$ Garayo Urruela \\ Gobierno Vasco \\ E-mail: imgaraio@euskalnet.net
}

\begin{abstract}
RESUMEN
El artículo representa una introducción a la teoría social formulada por Frédéric Le Play, pensador social clásico y considerado uno de los fundadores de las ciencias sociales contemporáneas.
\end{abstract}

Le Play desarrolló su actividad intelectual bajo la órbita de la escuela francesa, que, junto a la alemana e inglesa, comprenden las tres corrientes romántico-conservadoras europeas más importantes. Le Play, cuyo pensamiento estuvo directamente influido por L. de Bonald y J. de Maistre, elevó a categoría científica y modernizó las teorías moralistas de la escuela conservadora francesa al sacarlas de un contexto religioso-tradicionalista para incorporarlas a una propuesta enraizada en la ciencia positiva y el conservadurismo liberal.

${ }_{1}$ Este artículo reproduce de forma ampliada el texto del apartado dedicado a analizar el pensamiento social de Frédéric Le Play en la investigación presentada, bajo la dirección de D. Eduardo Sevilla Guzmán, como tesis doctoral en la Facultad de Sociología de la Universidad de Deusto (Bilbao) el 6 de marzo de 1998, con el título de La propiedad comunal en pensamiento social agrario: perspectivas sociológicas (Bilbao, 1999). 


\section{VIDA MARCADA POR LA ESTRECHA VINCULACIÓN DE LA CIENCIA SOCIAL CON LA PRAXIS POLÍTICA}

Pierre Guillaume Frédéric Le Play (1806-1882) nació en Riviere, pueblecito rural y pesquero próximo a Honfleur (Normandía), con fuertes tradiciones comunitarias. Este ingeniero de minas francés, por motivos profesionales, residió y visitó la mayoría de los países de Europa Occidental y aquellos de Asia colindantes con la misma ${ }^{2}$. La visita a países como Alemania, España, Rusia e Inglaterra tuvo especiales repercusiones en su formación y actividades intelectuales al representar la estancia en los mismos oportunidades para conocer directamente ejemplos concretos de organización estable de sociedades humanas, que se tradujeron en hitos en el proceso de formación y maduración intelectual ${ }^{3}$.

Le Play, entre 1830 y 1848, simultaneó las actividades desarrolladas en la Escuela de Minas (responsable de laboratorio, catedrático de Metalurgia, director de la revista Annales des Mines) con los estudios sociales y aprovechó sus visitas profesionales a distintos países para perfilar y poner a punto su proyecto de investigación en ciencias sociales ${ }^{4}$. Le Play, en cuanto reputado ingeniero de

${ }^{2}$ Datos biográficos, así como un resumen y una revisión del pensamiento de Le Play, pueden obtenerse en la lectura de E. DEMOLINS («Le Play et son oeuvre de réforme sociale», La Réforme Sociale, núm. 1 [1982], 409-423), de L. DE FOURCY («Le Play. L’ingenieur des mines», La Réforme Sociale, núm. 1 [1983], 29-44), de F. AuburTin (Federico Le Play según él mismo. Vida-Método-Doctrina. Datos y trozos escogidos, traducción de C. Gallardo, Madrid, Saturnino Calleja, S.A., I, 13-118), de P. Sorokin (Teorías sociológicas modernas, Buenos Aires, 1951), de N. TIMASHEFF (La teoría sociológica, México, FCE, 1961, 65-68), de R. NISBET (La formación del pensamiento sociológico, Buenos Aires, Amorrortu, 1977, 88-100), de R. FleTCHeR («Frédéric Le Play», en T. Raison [ed.], Los padres fundadores de la ciencia social, Barcelona, Anagrama, 1970, 51-58), de J. R. PITTS («Le Play, Fréderic», en D. L. Sills [dir.], Enciclopedia Internacional de Ciencias Sociales, Madrid, Aguilar, 1974, VI, 561-566), de B. KALAORA y A. SAVOYE ("Frédéric Le Play, un sociologe engagé», postfacio a F. Le Play [dir.], Ouvriers des deux mondes: etudes publiées par le Société d'Economie Sociale a partir de 1856, Thomery, A l'Enseigne de l'Arbre verdoyant editeur, 1983, 320-334; Forêt et sociologie, les forestiers de l'Ecole de le Play, defenseurs des populations de montagne [1860-1913], París, INRA, 1984, 20-27), de A. SAYOYE («Les continuateurs de Le Play au tournant de siécle», Revue Française de Sociologie, XXII [1981], 315-344, y en concreto las pp. 316-318), de L. Assier-ANDrIEU («Le Play et le famille-souche des Pyrénées: politique, jurisdisme et science sociale», Annales. Economies, Sociétés, Civilisations, núm. 3 [1984], 495-512).

${ }^{3} \mathrm{La}$ incidencia de los viajes profesionales en la formación intelectual de Le Play es analizada por L. de Fourcy, quien apuntó el carácter confirmatorio que los mismos tuvieron respecto a la idea de inspirarse en "las tradiciones del pasado» en cuanto solución alternativa a los problemas de las sociedades industriales (L. DE FOURCY, "Le Play. L'ingenieur des mines», La Réforme Sociale, núm. 1 [1883], 33).

${ }^{4}$ La transformación de Le Play, politécnico de formación, en pensador social se realizó por dos caminos complementarios. Le Play, en cuanto ingeniero, sintió necesidad de estudiar las condiciones de vida de los obreros empleados en minas y fábricas metalúrgicas, por lo que se vio abocado al campo de la investigación social. El estudio de la diversidad de condiciones sociales de existencia de los obreros europeos condujo a Le Play a la adopción de las reglas de trabajo científico en la investigación social, que pretendió convertirlas en análogas a las de las ciencias naturales (F. ARNAULT, "Frédéric Le Play, de la metallurgie a "la science sociale" ", Revue Française de Sociologie, XXV [1984], 437-457). 
minas y experto en organización social, participó en algunas de las comisiones de trabajo (creación de una escuela de la administración, condiciones de vida de los trabajadores) creadas por el Gobierno Provisional surgido de la Revolución de 1848. Le Play pudo comprobar directamente las escasas posibilidades de una alianza duradera entre las clases burguesa y obrera, por lo que abandonó pronto cualquier ilusión por reformar la sociedad por vía revolucionaria. La crisis de 1848 marcó el punto de transición de las actividades profesionales como ingeniero de minas y etapa formativa del pensamiento social a la dedicación completa al estudio de los problemas y las reforma sociales, que, en su opinión, se habían convertido en una cuestión inaplazable. En 1855 dimitió de los puestos docentes desempeñados en la Escuela de Minas (inspector de estudios, nombrado en 1848, y catedrático de Metalurgia) para consagrarse exclusivamente a la elaboración de una ciencia social, que el pensador francés consideraba el único medio posible de reforma social. Concretamente, en el año referido y con 49 años, publicó Les ouvriers européens. Esta obra contiene un cúmulo de noticias sobre las formas campesinas de apropiación del suelo, existentes entonces en Europa, y constituye la puesta a punto y exposición del método científico desarrollado por Le Play. La obra se compone de treinta y seis monografías seleccionadas entre las trescientas que llegó a escribir. En el apéndice final dedicado a las conclusiones prácticas, Le Play apuntó sus propuestas reformistas. La obra, que presenta los materiales documentales recopilados a lo largo de los años 1833-1853, sobre los que el pensador francés construyó sus teorizaciones sociales, se distingue por su voluminosa extensión, pero carece, sin embargo, de una sintética y sistemática exposición del pensamiento social leplaysianos.

La etapa de sistematización y maduración de la ciencia y reformas sociales leplaysianas coincidió con los años 1855 a 1870, años de máxima notoriedad pública, en los que Le Play se vio recompensado por sus actividades profesionales y científicas ${ }^{6}$ con el nombramiento para diversos cargos públicos: Conse-

F. Le Play, Les ouvriers européens. Etudes sur la travaux, la vie domestique et la condition morale des populations ouvrieres de l'Europe, précédées d'un methode d'observation, París, Impr. Impériale, 1855. En su segunda edición (Tours, A. Mame et Fils, 1877-1879, 6 vols.), Le Play, ya septuagenario, refundió y aumentó el contenido de la primera, a la que incorporó el discurso ideológico construido por el ingeniero de minas francés entre 1855 y 1870 . Les ouvriers européens, comprendiendo una serie de monografías (36 en la edición de 1855 y 57 en la de 1877-1879) e intercalando análisis macro y microsociológicos, contiene un estudio de campo de la estructura social, de las relaciones de ésta con el medio y del orden y de la desorganización social sobre la base de la interacción de fuerzas económicas y políticas. Resúmenes extractados de páginas y monografías de este voluminosa obra pueden consultarse en P. SOROKIN, C. ZIMMERMAN y Ch. GalPIn, A systematic Source book in Rural Sociology, New York, Russel and Russel, 1930, I, 350-353, y II, 76-94, 335-340. Las monografías relativas a España han sido publicadas por el Ministerio de Agricultura, Pesca y Alimentación: F. LE PLAY, Campesinos y pescadores del Norte de España: tres monografias de familias trabajadoras a mediados del siglo XIX, edición, introducción y notas a cargo de José Sierra Álvarez y Postfacio de Rafael Domínguez Martín, Madrid, MAPA, 1990.

${ }^{6}$ Los honores públicos disfrutados por Le Play en vida contrastan, sin embargo, con el olvi- 
jero de Estado (1855), Comisario General de la Exposición de París (1855 y 1867), Senador (1867), etc. Con la fundación de la Société d'Economie Sociale (1856), Le Play trató de canalizar el éxito conseguido con Les ouvriers européens hacia la constitución y organización de una red de colaboradores que prosiguiesen los estudios monográficos de familias según los esquemas y el método por él desarrollados. Esta sociedad científica se encargó de la publicación de los resultados alcanzados en las investigaciones emprendidas por sus miembros a través de Les ouvriers de deux mondes ${ }^{7}$. El programa de reformas sociales concebido por Le Play puede considerarse ultimado para 1864, año de publicación de La reforme sociale en France ${ }^{8}$, en donde, procediendo a un análisis de la sociedad francesa, sistematizó y sintetizó las diferentes medidas que estimaba convenientes para la estabilidad social general. El apoyo explícito mostrado por Napoleón III a las actividades y programas de reforma social propugnados por Le Play pareció dar visos de realidad a la estrategia intelectual leplaysiana consistente en la traducción política de las conclusiones deducidas del estudio científico de la realidad social. Le Play se apoyó en la autoridad carismática del Emperador para imponer la investigación sociológica (la vida industrial, la situación del sector de las panaderías en París, etc.) como técnica de gobierno y herramienta de reforma social. La ciencia estuvo, de esta forma, al servicio del poder establecido, que defendía la implantación en la sociedad francesa de un proyecto social conservador de corte autoritario.

Los fracasos cosechados en sus intentos de 1865 y 1869 para reformar el Código Civil en materia de herencias familiares y la caída del II Imperio en 1870 esfumaron las expectativas que Le Play se había creado al efecto, lo que determinó el paso a la vida privada y conllevó un giro de sus actividades hacia el reforzamiento de las labores organizativas y a las actividades de divulgación, buscando la difusión de su programa de reforma social. Entre los logros más

do actual profesado desde las instituciones académicas (M. DION, «Sociólogie et ideologie dominante dans l'oeuvre de Le Play et Durkheim», La Pensée, núm. 158 [1971], 55-56; J. R. PITTS, "Le Play, Frédéric», en D. L. Sills [dir.], Enciclopedia Internacional de Ciencias Sociales, Madrid, Aguilar, 1974, VI, 565). Un olvido fraguado, en opinión de José Sierra, en la permanente incomodidad planteada por un sistema de pensamiento como el leplaysiano que, en lo metodológico, sustentaba una concepción plurilineal del progreso social y encerraba una aguda crítica a los principios de la sociedad liberal formulados en la economía política, por lo que el mundo académico institucionalizado terminó esquivándolo por la vía de encerrarlo en el panteón del pensamiento reaccionario decimonónico (R. SIERRA ÁlvareZ, "Introducción: la obra de Le Play», en F. Le PlaY, Campesinos y pescadores del Norte de España, Madrid, MAPA, 1990, 14-15).

F. LE Play (dir.), Les ouvriers des deux mondes. Etudes sur les travaux la vie domestique et la condition morale des populations ouvriéres des diverses contrées et sur les rapports qui les unissent aux autres clases, París, Société Internationale d'Etudes Pratiques d'Economie Sociale, 1857-1885, 5 vols. Los textos de las monografías familiares más importantes han sido reeditados en Les ouvriers des deux mondes. Etudes publiés par le Société d'Economie Sociale á partir de 1856 sous le direction de Frédéric Le Play, postface par Bernard Kalaora et Antoine Savoye, Thomery, A l'enseigne de l'arbre verdoyant editeur, 1983.

${ }^{8}$ F. LE PLAY, La réforme sociale en France deduite de l'observation des peuples européens, París, 1864, 1. a edición, 2 vols.; Tours, A. Mame et Fils, 1887, 7. a edición. 
importantes de esta nueva etapa vital de Le Play hay que destacar, en el aspecto organizativo, Les Uniones de le paix sociale, y en el de vulgarización intelectual de sus teorías y propuestas sociales sobresale la publicación de obras como L'Organisation du travail' ${ }^{9}$ L'Organisation de la famille ${ }^{10}$ y La Constitution essentielle de l'Humanité'11.

Le Play protagonizó uno de los primeros intentos por construir una ciencia empírica de la sociedad, instrumentada metodológicamente en la observación inductiva y en la clasificación, y sustentada teóricamente en la defensa del patronazgo y de la familia troncal. Las propuestas intelectuales leplaysianas conforman una compleja unidad, en la que es preciso señalar tres rasgos principales: la perspectiva doctrinal, con la que se acercó a la realidad social; el método de investigación aplicado, y los resultados alcanzados, manifestados en la formulación de un programa de reforma social. Los tres aspectos formaron una unidad indisociable, aunque no exenta de contradicciones ${ }^{12}$. A continuación se desmenuzan, por separado y a efectos de presentación y exposición, los tres rasgos mencionados, inseparablemente unidos dentro del pensamiento leplaysiano.

9 F. Le Play, L'Organisation du travail, selon la Coutume des ateliers et la loi du Décaloque, Tours, A. Mame et Fils, 1888, 1. a edición.

${ }^{10} \mathrm{~F}$. LE Play, L'Organisation de la famille, selon le vrai modéle signalée per l'histoire de toutes les races et de tous les temps, Tours, Mame et Fils, 1871, 1. a edición.

${ }^{11}$ F. Le Play, La Constitution essentielle de l'humanité. Exposé des principes et des coutumes qui créent la prospérité ou la soufrance des nations, Tours, A. Mame, 1881, 1. a edición.

12 Una interpretación dualista del pensamiento leplaysiano ha sido realizada por Jesse R. PITTS («Le Play, Fréderic», en D. L. Sills [dir.], Enciclopedia Internacional de Ciencias Sociales, Madrid, Aguilar, 1974, VI, 564-565), por constituir una mezcla de positivismo e idealismo, y también por L. AsSIER-ANDRIEU («Le Play et la famille-souche des Pyrenées: politique, juridisme et science sociale», Annales, núm. 3 [1984], 495), quien ha diferenciado entre proyecto científico sociológico y proyecto político de reforma social. La mezcla leplaysiana de elementos teóricos incoherentes desembocó a su muerte, entre 1885-1886, en la escisión de la escuela de discípulos en dos ramas, una surgida en torno a La Réforme Sociale y liderada por Charles de Ribe, que profundizó en el componente político del pensamiento leplaysiano, y otra representada por Tocorville, De Roussiers, Robert Pinot, Eduard Demolins, etc., que, agrupados en torno a Science sociale, desarrollaron los contenidos positivistas y científicos del proyecto intelectual leplaysiano (J. R. PITTS, "Le Play, Frédéric», en D. L. Sills [dir.], Enciclopedia Internacional de Ciencias Sociales, Madrid, Aguilar, 1974, V, 564-565; A. SAVOYE, «Les continuateurs de Le Play au tournant du siécle», Revue Française de Sociologie, XXII [1981], 318-344). En este contexto, tiene sentido recoger la afirmación realizada por Gïde y Rist en los inicios del siglo XX: «La escuela de Le Play no está solamente caracterizada por una determinada doctrina, sino también por un método que, por otro lado, ha tenido más éxito que la doctrina y parece actualmente disfrutar de una vida independiente» (C. GÏDE y C. RIST, Histoire des doctrines economiques, París, Recueil, 1913, 577-578). 


\section{PREOCUPACIÓN TEÓRICA DOMINANTE: LA PAZ Y LA ESTABILIDAD SOCIALES}

La perspectiva desde la que Le Play procedió al estudio de la realidad social vino marcada por la articulación de doctrina y método y por una combinación de elementos tradicionales y modernos dentro de una propuesta conservadora de intervención social ${ }^{13}$.

Este ingeniero francés fue un hombre con principios morales, una persona políticamente conservadora que, desde la valoración positiva otorgada a la familia, manifestó duras críticas a la Ilustración y a la Revolución francesa de 1789 , a la que consideró la plasmación práctica de los principios defendidos por la primera ${ }^{14}$. A través de Rousseau, Le Play sintetizó las aportaciones de la Ilustración, en lo que él llamó los tres dogmas: el hombre es bueno por naturaleza, el origen de la violencia radica en las ideas e instituciones tradicionales y la destrucción de las mismas constituye un paso obligado para que el hombre, alcanzando la libertad, reencuentre el camino que le conduzca hacia el bien. La posición de Le Play, totalmente contraria a la de Rousseau, partía de una teoría del origen humano basada en la doctrina del "pecado original» de inspiración cristiana: el hombre por naturaleza era malo y, para conducirlo hacia el bien, era preciso reprimir coactivamente las prácticas humanas maléficas. Desde esta perspectiva, este autor francés creyó encontrar remedio a la problemática situación social de su tiempo en la jerarquía y la coacción, lo que le llevó a recomendar como solución a la maldad humana original la familia patriarcal y las «constituciones modelos» en cuanto formas de coacción paternal y gubernamental. Las propuestas leplaysianas de reforma moral contienen, por ello, una positiva valoración de las instituciones tradicionales.

Le Play, en su confrontación con la Ilustración, manifestó posiciones de rechazo a una concepción unilineal, progresiva e indefinida del progreso social. El contenido moral de sus planteamientos intelectuales permitió abordar el cambio socioeconómico y político de la sociedad burguesa y capitalista desde matizadas posiciones que, por un lado, le permitieron analizar críticamente las sociedades liberales de su tiempo y, por otro, mantener cierto equilibrio y respeto hacia valores e instituciones preliberales.

Los cambios sociales introducidos por las revoluciones burguesas habían socavado y destruido costumbres e instituciones sociales fundamentales hasta entonces y habían traído como consecuencia más palpable la inestabilidad política y social. La conflictividad social generada por las sociedades liberales era un tema que le preocupó especialmente. Según sus cuentas, entre el 14 de julio de 1784 y el 4 de septiembre de 1870 se habían producido en Francia diez

13 F. LE Play, La réforme sociale en France, París, 1887, 1-7.

${ }^{14}$ F. LE PlaY, Les ouvriers européens, Tours, A. Mame et Fils, 1878, VI, "épilogue», traducido y recopilado por F. Auburtin (comp.), Federico Le Play según él mismo. Vida-MétodoDoctrina-Datos y trozos escogidos, Madrid, Saturnino Calleja, S.A., 323-338. 
revoluciones ${ }^{15}$. La propuesta intelectual del ingeniero francés estuvo presidida por este hecho y estuvo marcada por la búsqueda de aquellos principios garantizadores de la paz, orden y estabilidad sociales, lo que él llamó la «verdad eterna», "la constitución esencial de la humanidad».

Por lo anterior, puede parecer que la propuesta del ingeniero francés es la de un nostálgico del Antiguo Régimen o la propia de un intelectual legitimista francés. Nada de eso. La especificidad de la propuesta intelectual de Le Play es la combinación de lo nuevo con lo arcaico, del orden con la libertad, del liberalismo con el tradicionalismo, del progreso social con la moralidad. Ello se plasmaba en un programa de reforma social que eliminase la desigualdades sociales más sangrantes, generadas por la transformación capitalista de la economía, y abriese camino a la paz y a la estabilidad sociales ${ }^{16}$, pero, siempre, dentro de unos límites que no traspasaron los principios marcados por el liberalismo político ${ }^{17}$.

\section{ESTRATEGIA INVESTIGADORA: ESTUDIO EMPÍRICO Y ANÁLISIS INTERCULTURAL DE LAS UNIDADES DOMÉSTICAS}

El proyecto leplaysiano de construcción de una ciencia social tuvo como principal objetivo la búsqueda de los criterios o indicadores que, con evidencia científica, permitieran identificar las causas de prosperidad o, en su defecto, decadencia de las sociedades humanas. El pensador francés, del mismo modo que anteriormente lo habían hecho pensadores sociales católicos como De Bonald y De Maistre ${ }^{18}$, comprendió que la culminación con éxito de los objeti-

15 Véase el epílogo del tomo sexto de Les ouvriers européens, Tours, A. Mame et Fils, 1878, reproducido en F. Auburtin (comp.), Federico Le Play según él mismo. Vida-Método-DoctrinaDatos y trozos escogidos, Madrid, Saturnino Calleja, S.A., 327.

16 A. SAvoye, "Les continuateurs de Le Play au tournant des siécle», Revue Française de Sociologie, XXII (1981), 318; B. KalaOra y A. SAVOYE, «Le Play et les fondements d'une sociologue forestiére», Milieux, núm. 21 (1985), 36; R. SIERrA ÁlVAREZ, «Introducción: La obra social de Le Play», en F. LE Play, Campesinos y pescadores del Norte de España, Madrid, MAPA, $1990,45$.

${ }^{17}$ El programa político leplaysiano rechaza el doctrinalismo liberal de la escuela manchesteriana de economía política, pero no por ello deja de ser un liberal. Le Play, como apuntaron Kalaora y Savoye, «... tensa la lógica liberal hasta el límite y en todos los ámbitos: económico, político, religioso, social...» (B. KALAORA y A. SAVOYE, "Frédéric Le Play, un sociologue engagé», en Ouvriers des deux mondes, Thomery, A l'enseigne de l'arbre verdoyant, 1983, 329). La reforma social leplaysiana aborda un programa de acción orientado a superar los límites del liberalismo con la solución de los problemas sociales desencadenados por el mismo. Gïde y Rist se refirieron a los miembros de la Escuela de Le Play, que, dentro de los pensadores socialcristianos, estaban «más próximos a la escuela liberal clásica» (C. GÏDE y C. RIST, Histoire des doctrines economiques, París, Recueil, 1913, 572).

${ }_{18}$ Joseph de Maistre (1753-1821) y Louis de Bonald (1754-1840) se convirtieron en las principales figuras del pensamiento conservador en Francia, corriente intelectual que denunció 
vos propuestos pasaba previamente por el rechazo de las teorías apriorísticas y la postergación de los prejuicios inculcados mediante la educación procedente del medio social de pertenencia, por lo que trató de apoyar las mismas con una base empírica, ajena a los maestros, que le sirvió de fuente de inspiración teórica. El politécnico francés creyó encontrar el camino que conducía a la identificación científica de los indicadores de prosperidad de las sociedades humanas, por medio de la observación de aquellos pueblos que ya disfrutaban de estabilidad y paz sociales. Las conclusiones extraídas por inducción de los hechos y datos recopilados mediante la observación permitían obtener, según los innovadores planteamientos metodológicos leplaysianos, los principios y leyes que dirigían y animaban las sociedades humanas y, en concreto, los factores intervinientes en la prosperidad y decadencia de las mismas.

Los viajes y estancias realizados por diferentes países desde 1829 a 1837 le permitieron conocer innumerables hechos y múltiples situaciones sociales, de los que extrajo la conclusión de que el sustrato básico de los pueblos (la verdadera constitución en terminología leplaysiana) radicaba en las ideas, costumbres e instituciones privadas, que eran las que, en definitiva, imprimían un carácter específico a la vida pública, y más concretamente en la familia, que se configuraba en el principio organizador y dinamizador del Estado.

El ingeniero francés, en su tentativa de encontrar a través de una búsqueda científica los elementos determinantes de una sociedad estable, partió de la hipótesis de que era posible acceder al conocimiento del estado social (decadencia, prosperidad, desorganización y estabilidad sociales) en que se encontraba una determinada sociedad por medio del estudio sistemático de una unidad microsocial convenientemente elegida ${ }^{19}$. Le Play detectó los problemas sociales más acuciantes entre las clases trabajadoras, a las que dedicó su actividad investigadora y atención intelectual. La unidad de estudio elegida por Le Play fue, por tanto, la familia obrera, entendida de forma amplia y comprensiva de todas aquellas personas de una familia que, ocupadas en trabajos manuales, trabajaban en actividades agrícolas, pesqueras, artesanales, industriales, etcétera ${ }^{20}$. El pensador francés encontró en la familia la unidad microsocial que le permitió conectar con los problemas sociales, construir un sistema

los puntos débiles de las democracias liberales y, en especial, las negativas consecuencias de la Revolución de 1789, origen de aquéllas, pero, a su vez, protagonizó un intento de señalar un camino alternativo a la misma, que persiguió la construcción de una sociedad armónica y jerarquizada sobre la base de la incorporación de los principios morales cristianos en la organización del Estado y la recuperación selectiva de costumbres colectivas ancestrales (J. MAISTRE, Essai sur le Principe genérateur des Constitutions Politiques, Lyon, J. B. Pelagand et Cie., 1858; L. DE Bonald, Demonstration Philosophique du Principe Constitutif de la Société, París, Libraire Adrien Le Clere et Cie., 1840).

19 A. SAVOYE, «Les continuateurs de Le Play au tournant des siècle», Revue Française de Sociologie, XXII (1981), 316-317 y 322.

${ }^{20}$ Le Play, cuando hablaba de clases obreras, se refiere a ellas en un sentido lato del término, abarcando a todas aquellas personas ocupadas en trabajos manuales (F. LE PLAY, La réforme sociale..., Tours, A. Mame et Fils, 1887, XLVIII). 
de ciencia social y plantear los ejes del programa de reformas. La familia, en el esquema leplaysiano de indagación teórica, se convierte en objeto de investigación, dogma científico y fundamento a la vez que principio del orden social. Le Play, desde la perspectiva anterior, encaminó su indagación intelectual a la observación minuciosa y detallada del mayor número posible de familias con el objeto de descubrir las raíces profundas de la prosperidad y decadencia de las sociedades humanas.

La propuesta de reforma social de Le Play vino acompañada de la reflexión metodológica y la innovación en las técnicas de investigación, lo que le ha convertido en uno de los pioneros del trabajo de campo en las ciencias sociales ${ }^{21}$. Este autor francés, en sus investigaciones de la familia obrera, utilizó el método de la observación directa sobre el terreno y aplicó la técnica de investigación conocida por el método histórico de observación de casos, que en el autor adquirió la forma de monografías familiares basadas en una encuesta de presupuestos familiares complementada con una serie de informaciones cualitativas proporcionadas por personajes influyentes orientadas a situar la familia estudiada en su medio de desenvolvimiento social ${ }^{22}$. El método leplaysiano de las monografías familiares, inspirado en los sistemáticos informes que los estudiantes de la Escuela de Minas realizaban sobre el terreno en los trabajos de fin de carrera, concedía un particular relieve a aquellos datos y elementos que podían ser recogidos directamente y sometidos a medición y tabulación estadística $^{23}$. El método leplaysiano estableció dentro de las ciencias sociales la práctica del trabajo de campo y constituyó un incipiente anticipo de lo que, con el tiempo, derivó en los métodos de construcción de índices y en la teoría del muestreo.

La clasificación trataba de integrar y organizar los múltiples hechos recopi-

${ }^{21}$ La sociología empírica anglosajona ha reivindicado a Le Play como precursor por la orientación cualitativa de su propuesta metodológica (P. L. LAZARSFELD, «Le Play et sa methode d'observation", en Philosophie des sciences sociales, París, Gallimard, 1970, 129-162; R. BoudON, "An introduction to "Lazarsfelds" Philosophical Papers", en P. L. LAZARsfeld, Qualitative Analysis. Historical and Critical Essays, Boston [1972], 420-422).

${ }^{22}$ Le Play dedicó el primero de los seis tomos que comprendía Les ouvriers européens a la exposición de los orígenes, descripción e historia de los resultados de la aplicación del método de observación al estudio de las familias obreras. Le Play volvió sobre el tema en sus obras posteriores (véase La réforme sociale en France deduite de l'observation comparée des peuples européens, Tours, Alfred Mame et Fils, libraires-editeurs, 1887, 7. a edición, capítulos 7 y 8). A través de la observación y el raciocinio, Le Play buscó "la verdad eterna», "la constitución esencial de la humanidad", es decir, unos principios eternos, garantizadores de la libertad y el orden sociales. Le Play, en cualquier caso, protagonizó un método de investigación social desde preocupaciones e intereses industriales, que posteriormente tuvo una continuidad y desarrollo en los trabajos de pensadores franceses como Halbwachs y Chombart de Lauwe (F. FERraroti, Hombres y máquinas en la sociedad industrial, Barcelona, Labor, 1976, 154-155).

${ }^{23}$ Cf., en este sentido, los artículos de E. Demolins («Le Play et son oeuvre de réforme sociale», La Réforme Sociale, núm. 1 [1882], 411) y J. R. PITTS («Le Play, Frédéric», en D. L. Sills [dir.], Enciclopedia Internacional de Ciencias Sociales, Madrid, Aguilar, 1974, VI, 564565). 
lados en las monografías familiares ${ }^{24}$, que, mediante la comparación ${ }^{25}$, manifestaban tener un mismo carácter bien determinado. Aquí es preciso situar la taxonomía leplaysiana de la familia (patriarcal, inestable, troncal) o de las diferentes situaciones de los obreros (obreros domésticos, jornaleros, destajistas, obreros arrendatarios, obreros de oficio, obreros propietarios y propietarios obreros). Combinando observación empírica, clasificación y comparación intercultural, Le Play trató de identificar los elementos invariantes contribuyentes a la estabilidad social.

\section{LA RECUPERACIÓN DE LAS INSTITUCIONES SOCIALES INTERMEDIAS, BASE DE LA REFORMA SOCIAL LEPLAYSIANA}

La felicidad humana, la prosperidad y, en definitiva, la estabilidad social, núcleo de sus preocupaciones teóricas, estaban unidas en el esquema de pensamiento social leplaysiano a la satisfacción de las necesidades humanas más vitales: la práctica de los principios morales y el alimento diario ${ }^{26}$. La cobertura satisfactoria del doble contenido dado a las necesidades humanas dependía de siete elementos agrupados en tres bloques, que, respectivamente, denominó "estructuras», "cimientos» y "materiales» del edificio social: en las «estructuras» del edificio social, Le Play incluyó la ley moral universal o decálogo y la autoridad paterna; en los «cimientos» colocó las instituciones eclesiásticas, la religión y el gobierno político, mientras que en los «materiales» situó la propiedad comunal, la propiedad individual y el patronazgo, entendidas éstas no en

${ }^{24}$ F. Le Play, mediante la aplicación rigurosa del método, persiguió realizar «una especie de autopsia del cuerpo social, de clasificación de los hechos observados en un orden científico» (E. Demolins, «Le Play et son oeuvre de réforme sociale», La Réforme Sociale, núm. 1 [1882], 415).

${ }^{25}$ El estudio comparativo realizado por Le Play sobre la vida económica y social de campesinos, artesanos, pescadores y demás trabajadores europeos constituye el punto de partida de la consideración de este autor francés como precursor de los estudios etnológicos («Encuestas», en Enciclopedia Universal Ilustrada Europea-Americana, Madrid, Espasa-Calpe, 1929, XIX, 1238) y antropológicos de las sociedades modernas (W. GOLDSCHMIDT, "Antropología-V: El estudio antropológico de la sociedad moderna», en D. L. Sills [dir.], Enciclopedia Internacional de Ciencias Sociales, Madrid, Aguilar, 1974, I, 413). Las relaciones establecidas entre naturaleza y sociedad con intermediación del trabajo y la tecnología apuntadas por Le Play le convierten en un precedente de la geografía y de los fundadores de la geografía regional. Cf., en este sentido, J. Brunhes, Geografía Humana, Barcelona, Editorial Juventud, 1948, 268; A. ButTIMER, Sociedad y medio en la tradición geográfica francesa, Barcelona, Oikos-Tau, 1971, 34-37; P. Claval, Evolución de la geografía humana, Barcelona, Oikos-Tau, 1981, 154; H. CAPEL, Filosofía y ciencia en la geografía contemporánea, Barcelona, 1981, 297 y 300. Le Play fue un pensador social que, al analizar las relaciones entre medio natural y organización social, resaltó la importancia mantenida en este sentido por los territorios arbolados y, desde esta perspectiva, suele considerarse también pionero e iniciador de la sociología forestal. Para una revisión del enfoque forestal desarrollado por Le Play, acúdase a B. KalaOra y A. SAVOYE, "Le Play et les fondements d'une sociologie forestiere», Milieux, núm. 21 (985), 31-38, y La Forêt Pacifiée, París, L'Harmasttan, 1986, 29-34.

${ }^{26}$ F. LE Play, Les ouvriers européens, Tours, A. Mame et Fils, 1879, I, 132-134. 
cuanto formas jurídicas de apropiación, sino en cuanto elementos de relación social e instituciones reguladoras de la acción social colectiva ${ }^{27}$. Los elementos integrados en las «estructuras» y «cimientos» del edificio social, es decir, ley moral y autoridad paterna más religión y gobierno, estaban orientados a la satisfacción de las necesidades morales, mientras que el tercero, las diferentes organizaciones sociales de apropiación de los recursos materiales, cubría las necesidades humanas de subsistencia.

La forma cómo se organiza en cada sociedad la transmisión hereditaria de la propiedad y la regulación de la actividad social general determinaba, según la propuesta leplaysiana, una diferente capacidad de asimilación e integración armónica de los cambios sociales, lo que, en definitiva, marcaba un distinto grado de estabilidad-inestabilidad sociales. Le Play, por sus investigaciones interculturales de los regímenes consuetudinarios de herencia familiar y de las distintas fórmulas de organización de la actividad social, creyó llegar a identificar a la familia troncal y al patronazgo como formas de relaciones sociales más favorables para la estabilidad social ${ }^{28}$.

La propiedad privada, conforme al esquema leplaysiano de pensamiento, comporta múltiples ventajas sociales en la medida que están extendidas y desarrolladas conductas como el ahorro y la laboriosidad, y los propietarios, sin interferencia de los poderes públicos, disponen y manejan los patrimonios poseídos a su antojo y tienen libertad para transmitirlos a los herederos a su voluntad. Este régimen de propiedad, sin embargo, trae, en el caso del relajamiento de costumbres y caída de la actividad laboral, fatales e imprevisibles consecuencias para la sociedad manifestadas en la extensión de las enfermedades, del vicio, etc., y, en definitiva, de miseria. Las negativas consecuencias por la propiedad individual, según el estudio leplaysiano, conseguían, sin embargo, ser contrarrestadas con el patronazgo. El patronazgo puede revestir múltiples formas (el fundum germánico, la recommandatio en la sociedad francesa, la "clientela" en la sociedad romana y gálica, etc.), pero todas ellas reúnen la característica común de enlazar por el establecimiento de relaciones más o

${ }^{27}$ F. Le Play, Les ouvriers européens, Tours, A. Mame et Fils, 1879, I, 111-117.

${ }^{28}$ F. Le PlaY, "Paysans en communautés du Lavedan (Hautes-Pyrénées. France)», en F. Le Play (dir.), Les ouvriers des deux mondes, París, 1857, I, 107-160, y en especial las pp. 109-110 y 141-151; texto reproducido íntegramente en F. LE PLAY, L'Organisation de la famille selon le vrai modéle signalé par l'histoire de toutes les races et de tous les temps, Tours, A. Mame et Fils, 1871, 116-212. En 1869, Emile Cheysson, discípulo de Le Play, efectuó una funda encuesta a la familia de la casa "Mélouga», mayor resultados aparecieron publicados como epílogo en F. LE PLAY, L'Organisation de la famille, Tours, A. Mame et Fils, 1871, y en sucesivas ediciones de la misma Le Play incluyó entre los ejemplos vivientes y modélicos de estabilidad y prosperidad social a instituciones peninsulares, y en concreto a la organización social del País Vasco (F. LE PLAY, Les ouvriers européens, Tours, A. Mame et Fils, 1879, I, 117 y 140), lo que explica la publicación parcial de la memoria presentada con ocasión de la Exposición Universal de París de 1867 por Antonio de Trueba (Bosquejo de la organización social de Vizcaya, Bilbao, Juan Delmas Impresor, 1870) y de la correspondencia personal que con tal motivo estableció A. TRUEBA (Bosquejo de la organización social de Vizcaya, Bilbao, Juan Delmas Impresor, 1870, 5-18; F. LE PLAY, Campesinos y pescadores del Norte de España, Madrid, 1990, 119-120). 
menos estrechas un determinado número de familias pobres a otra rica que, mediante protección y trabajo, les garantiza el sustento diario y la supervivencia vital ${ }^{29}$.

La teoría del patronazgo sostenida por Le Play conforma una síntesis de temas tomados de Saint-Simon y del catolicismo social. El pensador francés se inspiró en ideas saint-simonianas como la organización y dirección de los trabajadores o la distinción entre élites dirigentes y dominantes ${ }^{30}$. De VilleneuveBargemmt, católico de tendencia conservadora, tomó, en cambio, la idea de patronazgo $^{31}$. Le Play, a partir de los elementos señalados, formuló una teoría de la autoridad social que derivó hacia un catecismo de «buen pastor» que, ante todo, debía respetar el decálogo. La fórmula revelada a Le Play por el análisis cientifista para organizar las clases populares y combatir la creciente desigualdad social generada por la sociedad capitalista industrial consistió, por tanto, en la generalización del sistema de patronazgo. Le Play, en su análisis sociológico de los diversos elementos que conforman la "constitución esencial» de las sociedades humanas, identificó determinadas prácticas sociales complementarias, el régimen de sucesión familiar entre ellas, que contribuían a asegurar el funcionamiento estable de las mismas. El pensador francés, con objeto de sintetizar el cúmulo de datos derivados de la vasta investigación comparativa emprendida, propuso un esquema clasificatorio de las sociedades humanas en base a la familia, dentro de la cual llegó a distinguir tres tipos de organización diferentes: las familias patriarcal, inestable y troncal ${ }^{32}$.

La familia patriarcal, compuesta por la asociación de hasta cuatro generaciones distintas, habita una misma casa y explota en comunidad bajo la autoridad del cabeza de familia el patrimonio familiar, lo que facilita la transmisión de las ideas y costumbres desde los más viejos a los más jóvenes. Este tipo de familia, según las investigaciones leplaysianas, era muy común en los pueblos pastores de Oriente, los campesinos rusos y los eslavos de Europa Central. La familia inestable, según la descripción del pensador francés, estaba formada por un núcleo familiar constituido por padres e hijos que, al llegar a la edad adulta, la abandonan para formar su propia familia y, una vez muertos los padres y disuelta la unidad convencional, se reparten el patrimonio familiar. La familia inestable se acerca bastante a la que, en la actualidad, se conoce por

29 F. Le Play, La réforme sociale..., Tours, A. Mame et Fils, 1887, I, 237.

${ }^{30}$ Para una exposición sintética de estas ideas de Saint-Simon puede verse F. PerrouX, Industrie et création collective, París, PUF, 1964, 16-31.

31 F. LE Play, La réforme sociale..., Tours, A. Mame et Fils, 1887, I, 237.

32 Frédéric LE PlaY abordó la descripción de los diferentes tipos de familia en L'Organisation de la famille, Tours, A. Mame et Fils, 1871, 9-11. En cuanto revisión crítica de las teorías leplaysianas respecto a la familia, acúdase a H. Lefevre (coord.) («Structures familiales comparées», en G. Friedmann [ed], Villes et campagnes, París, A. Colin, 1953, 327-362) y a L. Assieur-ANdrieu («Le Play et la famille-souche des Pyrenés: politiques, jurisdisme et science sociale», Annales, núm. 3 [1984], 495-512). Un breve comentario del tratamiento leplaysiano sobre esta cuestión puede encontrarse en E. DEMOLINS («Le Play et son oeuvre de réforme sociale», La Réforme Sociale, núm. 1 [1882], 419-421). 
familia nuclear y, por la época que vivió Le Play, se extendía entre las clases obreras y burguesas residentes en medios urbanos. La familia troncal integra bajo un mismo techo a tres generaciones: los padres y hermanos solteros viven en comunidad con un hijo casado, concretamente al que se transmite el patrimonio familiar íntegro (una vez deducidos los importes de las dotes entregadas a los hijos que abandonan la casa familiar para establecerse fuera de la misma), y los descendientes de aquél. La salida forzosa del resto de los hijos en la familia troncal, sin poner en peligro la fecundidad y reproducción demográfica, contribuye a estabilizar y perpetuar las tradiciones y el patrimonio familiar. La familia troncal era un tipo de organización familiar todavía común entre las familias de pescadores y de campesinos de comunidades rurales ubicadas en las zonas de montaña del Occidente europeo.

La familia troncal se configura así en un régimen familiar intermedio entre la asfixiante rutina de la familia patriarcal y el excesivo individualismo de la familia inestable, por lo que reunía las ventajas inherentes a cada una de ellas. La familia troncal compagina, por ello, la moralidad ejemplar de la familia patriarcal y el desarrollo de la riqueza individual fomentado por la familia inestable. La familia troncal, en opinión de Le Play, garantizaba el mantenimiento del control social, el progreso de las instituciones, la libertad civil y, en definitiva, se configuraba en una especie de panacea para resolver los antagonismos de clase en las sociedades industriales ${ }^{33}$. La familia campesina que habitaba en el pueblo pirenaico de Lavedan la casa denominada Meluga ${ }^{34}$ pasó, en el contexto anterior referido, a convertirse en el arquetipo de la familia troncal y la piedra angular del programa reformista leplaysiano.

La particular atención prestada por Le Play a los regímenes de herencia familiar radica en la actualidad política que estas cuestiones presentaban en un momento histórico en el que las contradicciones entre el sistema legal de ámbito nacional francés, es decir, el Código Civil, y las prácticas sucesorias seguidas por el campesinado de pueblos pirenaicos de montaña se manifestaron con diáfana crudeza. La praxis intelectual y política de Le Play, en este contexto, estuvo orientada a combatir los instrumentos legales y procesos sociales que contribuyeron a la destrucción de formas de organización social que, como las campesinas, eran portadoras de estabilidad social para las zonas y los medios rurales franceses ${ }^{35}$.

Le Play trató de combatir el pauperismo y desarraigo social generados por la industrialización con la consolidación de la familia entre las clases trabajadoras y, más inmediatamente, por la integración de éstas en empresas familiares a través de la institución del patronazgo. La empresa familiar constituía un marco para las relaciones de tipo paternal, que facilitaba la eliminación de 152.

${ }^{33}$ Ver, en este sentido, F. LE Play, L'Organisation de la famille, Tours, Mame, 1871, 106 y

${ }^{34}$ F. LE Play, Les ouvriers européens, Tours, A. Mame et Fils, 1879, I, 111-117; La réforme sociale en France, Tours, A. Mame et Fils, 1887, 7. ${ }^{a}$ edición, II, libro VI.

${ }^{35}$ F. LE Play, Les ouvriers européens, Tours, A. Mame et Fils, 1879, I, 188 y 289. 
situaciones conflictivas y, por otro, abría oportunidades múltiples para el establecimiento de contratos permanentes y la participación de los trabajadores en la propiedad de las empresas. La organización social concebida por Le Play responde, por tanto, a una versión idealizada y modificada del papel económico y social a desempeñar por las pequeñas empresas, y más concretamente por las pequeñas empresas familiares ${ }^{36}$.

La predilección de Le Play por la familia troncal y por el patronazgo, expresada reiterada y manifiestamente a lo largo de su creación intelectual, queda de alguna forma relativizada al enmarcarlas en la importancia que el estado moral de la sociedad alcanza en su esquema intelectual de pensamiento. El estado moral de cada sociedad condicionó el que el pensador francés, con el objetivo de alcanzar la estabilidad social y conforme la fase determinada de desarrollo social en que aquélla se encontraba, recomendase una u otra forma social.

Le Play se manifestó contrario a las visiones monolineales, tecnocráticas y optimistas del progreso social. La concepción cíclica y multilineal que Le Play sostuvo en este punto influyó en el análisis realizado sobre las formas sociales de propiedad, a las que, desde el punto de vista analítico, colocó siempre en un plano de igualdad, sin más preferencia teórica entre ellas que las marcadas por el estudio evolutivo en que se encontraba la organización institucional de la sociedad estudiada. Propiedad privada y propiedad comunal presentaban formas distintas de organización social de la apropiación de los recursos materiales, que el ingeniero francés abordó sin análisis preconcebidos a favor o en contra, no obstante haber comprobado en sus investigaciones una tendencia marcada, constatable desde la Edad Media, hacia un régimen individual de la propiedad de la tierra: «La experiencia diaria pone de manifiesto que la propiedad se convierte en más fecunda en la medida que el propietario es dueño de disfrutarla a su antojo y de transmitirla sin interferencias de la autoridad pública» ${ }^{37}$. En determinadas circunstancias de organización viciosa o de corrupción humana, ambos regímenes de organización social de la apropiación económica podían transformarse en elementos de agitación y antagonismo sociales. Por el contrario, un reparto equilibrado de la propiedad de la tierra conducía al bienestar general, la seguridad y la estabilidad social. Para Le Play, lo importante, por tanto, no era la forma de organización de la propiedad, sino el uso que se hiciese de la misma ${ }^{38}$. El inge-

${ }^{36}$ Ver, en este sentido, J. R. PITTS, "Le Play, Frédéric», en D. L. Sills (dir.), Enciclopedia Internacional de Ciencias Sociales, Madrid, Aguilar, 1974, VI, 562. La predilección de Le Play por la familia troncal y por el patronazgo, expresada recurrente y manifiestamente a lo largo de su creación intelectual, queda de alguna forma relativizada al enmarcarlos en la importancia que el estado moral de la sociedad alcanza en su esquema intelectual de pensamiento. El estado moral de cada sociedad condicionó el que el pensador francés, con el objetivo de alcanzar la estabilidad social y conforme la fase determinada de desarrollo social en que aquélla se encontraba, recomendase una u otra forma social.

37 F. LE Play, La réforme sociale..., Tours, A. Mame et Fils, 1887, I, 237.

${ }^{38}$ El apartado cuarto del capítulo 16, dedicado a la propiedad libre e individual, lleva por título "La propiedad causa de prosperidad o de sufrimiento según el uso que se haga de la misma» (F. LE Play, La réforme sociale..., Tours, A. Mame et Fils, 1887 [7.a], 239 y ss.). 
niero francés no asoció, en cualquier caso, el comunitarismo con el igualitarismo, a los que más bien consideró términos opuestos, sino que, dado el control ejercido por los grupos oligárquicos sobre el poder, los patrimonios territoriales y la vida rural locales, los bienes comunales constituían recursos productivos empleados fundamentalmente por grandes propietarios, por lo que sostenía que era más acertado relacionar las instituciones comunales con el "patronazgo"

La valoración hecha por Le Play sobre los comunales fue ambivalente. Por un lado, las investigaciones de campo le permitieron comprobar que "este régimen de comunidad (de bienes) inicia a las poblaciones en los hábitos de la propiedad individual al tiempo que los preserva de las calamidades públicas» ${ }^{40}$. Los bienes comunales facilitaban medios y recursos complementarios a los disponibles en el régimen de propiedad privada, lo que, en definitiva, facilitaba la persistente conservación del campesinado y ofertaba de forma gratuita medios de vida que garantizaban a la población las condiciones mínimas de subsistencia ${ }^{41}$. Por otro, la inmovilización de amplias superficies de tierra en manos de las comunidades rurales obstaculizaba e impedía la mejora y desarrollo de explotaciones individuales emprendoras por medio de la renta de los comunales ${ }^{42}$. «Esta doble influencia - concluye Le Play — tiende, pues, a restringir el desarrollo natural tanto de la pobreza como de la riqueza ${ }^{43}$. La ambivalencia otorgada a los comunales motivó un abanico de soluciones posibles a aplicar en dependencia del estado moral de las poblaciones: "la tan espinosa cuestión de los bienes comunales es una de esas que no puede ser resuelta en el terreno de los principios; la solución se encuentra absolutamente subordinada al estado moral de las poblaciones» ${ }^{44}$. La recomendación del reparto de los comunales entre los campesinos usuarios y la venta a propietarios grandes estaba en función del grado de desenvolvimiento y de las ventajas derivadas de la propiedad que hayan alcanzado las poblaciones afectadas y, en la circunstancia de que dichas ventajas no estuviesen presentes, Le Play optaba por el mantenimiento de la propiedad comunal como «la más segura garantía del bienestar de las poblaciones» ${ }^{45}$.

39 R. Domínguez, El campesino adaptativo, Santander, Universidad de Cantabria, 1995, 192.

40 F. LE Play, "Familia campesina de Revilla de Camargo (Santander)», en F. Le Play, Campesinos y pescadores del Norte de España, Madrid, MAPA, 1990, 113.

${ }^{41}$ F. LE Play, Les ouvriers européens, Tours, A. Mame et Fils, 1879, I, 112-113; F. LE PLAY, "Familia campesina de Revilla de Camargo (Santander)", en F. LE PLAY, Campesinos y pescadores del Norte de España, Madrid, MAPA, 1990, 114.

42 F. LE PlaY, "Familia campesina de Revilla de Camargo (Santander)», en F. LE Play, Campesinos y pescadores del Norte de España, Madrid, MAPA, 1990, 114.

43 F. LE PlaY, "Familia campesina de Revilla de Camargo (Santander)», en F. LE Play, Campesinos y pescadores del Norte de España, Madrid, MAPA, 1990, 114.

44 F. LE PlaY, "Familia campesina de Revilla de Camargo (Santander)», en F. LE Play, Campesinos y pescadores del Norte de España, Madrid, MAPA, 1990, 115.

45 F. LE PlaY, "Familia campesina de Revilla de Camargo (Santander)», en F. LE Play, Campesinos y pescadores del Norte de España, Madrid, MAPA, 1990, 115; F. LE PLAY, La réforme sociale en France, Tours, A. Mame et Fils, 1887, 7. a edición, III, 477-478. 
El análisis social leplaysiano sobre la propiedad, la familia y el trabajo se completan con el estudio de la organización política. Le Play, en este ámbito de la realidad, partió de la situación de paz y estabilidad sociales, constatadas mediante observación, que disfrutaban aquellos pueblos que respetaban la ley divina y cumplían los preceptos del decálogo y, además de la sumisión a la ley moral, se manifestaban obedientes con la autoridad soberana y poderes estable$\operatorname{cidos}^{46}$. La autoridad estaba revestida según el ámbito de ejercicio (familia, municipio, provincia y Estado) de un carácter diferente: teocrático en el ámbito individual, democrático en el municipal, aristocrático en el provincial y monárquico en el familiar y estatal. El programa político leplaysiano puede sintetizarse en los siguientes términos: centralización política y descentralización administrativa. Al Estado le atribuye la aprobación de las leyes, el ejército, la relaciones exteriores, la hacienda, la justicia, la policía y la beneficencia. El resto, es decir, la administración provincial y local, el culto, la educación, la sanidad, las comunicaciones viarias, el comercio, la industria, etc., pasan, bajo algunas reservas, a ser competencia de las entidades locales, las asociaciones profesionales y los individuos. La intervención del Estado se circunscribe a lo indispensable. En la propuesta leplaysiana, la necesidad de intervención del Estado en ámbitos competenciales de municipios y regiones no era sino una manifestación, como señalaron Gïde y Rist ${ }^{47}$, de «un estado patológico», que reflejaba la extensión del fenómeno de la inestabilidad social.

En definitiva, la reforma leplaysiana de la sociedad, tal como él mismo la resumió en el epílogo del tomo sexto de Les ouvriers européens, era una combinación de tradición e innovación: «Refiriéndose al estudio de la historia y las enseñanzas de los sabios, se puede resumir en las tres reglas siguientes la prácti-

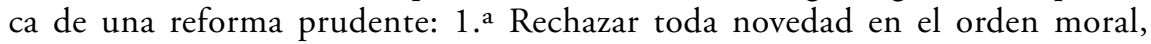
principalmente en lo que se refiere a los dos fundamentos eternos: el Decálogo y la autoridad paterna. 2. ${ }^{a}$ Restaurar las instituciones que, habiendo estado en vigor en la época de la prosperidad nacional, se conservan o se mejoran en los pueblos contemporáneos considerados como modelos de opinión del público. 3. a Imitar las nuevas costumbres adoptadas por los pueblos modelos. Los reformadores, en resumen, deben tomar como punto de partida de sus esfuerzos la observación metódica de las sociedades que han prosperado en todas partes y que prosperan hoy» ${ }^{48}$. En cualquier caso, el principio básico de la reforma social propuesta por Le Play consistía en una vuelta hacia las ideas, las costum-

${ }^{46}$ C. GÏDE y C. RIST, Histoire des doctrines economiques, París, Recueil, 1913, 573-574.

47 Un breve análisis comentado de las ideas sostenidas por Le Play en cuanto a la organización política de la sociedad puede encontrarse en E. DEMOLINS, "Le Play et son oeuvre de réforme sociale», La Réforme Sociale, núm. 1 (1882), 421-422. La oposición de Le Play a la creciente intervención del Estado en el ámbito social entra, sin embargo, en contradicción con las tendencias tecnocráticas que transpira su programa de reforma social (A. SAVOYE, «Les continauteurs de Le Play au tournant du siècle», Revue Française de Sociologie, XXII, 1981, 318).

${ }^{48}$ F. Auburtin (comp.), Federico Le Play según él mismo. Vida-Método-Doctrina. Datos y trozos escogidos, traducción de C. Gallardo, Madrid, Saturnino Calleja, S.A., vol. II, 330. 
bres y las instituciones sociales que, conciliando prosperidad económica con la práctica de las leyes morales, habían asegurado en distintas épocas a cada país los momentos de mayor prosperidad social ${ }^{49}$. En la opinión del autor francés, las instituciones que mejor plasmaban tales principios e ideas eran las instituciones sociales intermedias (familias troncales, empresas familiares, entidades locales...).

\section{CLAROSCUROS DEL PROYECTO INTELECTUAL LEPLAYSIANO}

La vida y pensamiento leplaysianos comporta una unidad entre teoría y práctica y entre doctrina y método no exenta, por supuesto, de algunas contradicciones. La vida y pensamiento de Le Play, por su condición de «pensador social comprometido" ${ }^{50}$ con los problemas de las sociedades liberales decimonónicas, comporta una remarcable invitación a la articulación de la teoría con la práctica, de la doctrina con el método, de la ciencia con el poder político ${ }^{51} \mathrm{y}$, en definitiva, a la construcción de una ciencia social que, por la vía de plantear soluciones a los problemas socioeconómicos generados a las sociedades de capitalismo industrial, contribuyera a facilitar y garantizar el buen funcionamiento de las mismas. Le Play concibió la ciencia social como un instrumento de cambio social orientado a legitimar y consolidar un proyecto de transformación de la sociedad favorable a los intereses económicos de los sectores sociales poderosos.

Le Play concibió la ciencia social como una forma rigurosa de descripción de la realidad social de la que, en forma evidente, se derivaban los orígenes de la felicidad individual y las causas de la armonía y paz sociales. El pensador francés, mediante el método de la monografía familiar, procedió a acumular datos que suponía que hablarían por sí mismos ${ }^{52}$ mediante la confección de unas cuantas monografías familiares suficientes, en su opinión, para convencer al lector de la conveniencia y los efectos sociales positivos del cumplimiento de las leyes morales básicas ${ }^{53}$. La acumulación de datos sin más dice relativamente

${ }^{49}$ El epílogo de 1878 contenido en el tomo VI de Les ouvriers européens (Tours, A. Mame et Fils, 1877-1879, 2. a edición) está distribuido en dos apartados, que llevan los significativos títulos de «EL PRINCIPIO DE LA REFORMA: SUSTITUIR EN LAS IDEAS EL ERROR FUNDAMENTAL DEL SIGLO XVIII CON LA VERDAD ETERNA DE LOS PUEBLOS PRÓSPEROS» y "LA PRÁCTICA DE LA REFORMA: SUSTITUIR, EN LAS INSTITUCIONES, LAS LEYES ESCRITAS DICTADAS POR EL ERROR POR LAS COSTUMBRES DE LA VERDAD ETERNA».

50 B. KalaOra y A. SAVOYe, "Frédéric Le Play, un sociologue engagé», postfacio a Ouvriers des deux mondes, Thomery, A l'enseigne de l'arbre verdoyant, 1983.

51 R. Sierra Álvarez, «Introducción: la obra social de Le Play», en F. Le Play, Campesinos y pescadores del Norte de España, Madrid, MAPA, 1990, 15.

52 Cf. en este sentido el trabajo de J. R. PITTs, «Le Play, Frédéric», en D. Sills (dir.), Enciclopedia Internacional de Ciencias Sociales, Madrid, Aguilar, 1974, VI, 565.

${ }_{53} \mathrm{La}$ continuidad entre método y doctrina en el pensamiento de Le Play es apuntada por 
muy poco si los mismos no se encuadran en una perspectiva comparativa y dentro de un cuerpo de proposiciones teóricas. Le Play, a pesar de su rechazo a los planteamientos apriorísticos, consiguió introducir orden y sentido en los datos acumulados por los principios teóricos y selectivamente comparativos derivados de un esquema teórico dominado por un ideario religioso y moralizante $^{54}$. La ciencia concebida por Le Play no consistió en un cuerpo acumulativo de proposiciones teóricas validadas por métodos experimentales. La recopilación de datos por medio de técnicas de campo, como las monografías familiares, representaba un recurso más bien retórico ${ }^{55}$ e «ilustrativo» ${ }^{56}$ que un riguroso intento de prueba para confirmar por vía inductiva unos determinados planteamientos teóricos ${ }^{57}$.

A. SAVOYE («Les continuateurs de Le Play au tournant du siècle», Revue Française de Sociologie, XXII, 1981, 317), B. KalaOra y A. SAVOYE («Frédéric Le Play, un sociologue engagé», en Ouvriers des Deux Mondes: Études Publiées par la Société d'Economie sociale á partir de 1856 sous la direction de Frédéric Le Play, Thomery, a l'enseigne de l'arbre verdoyant, 1983, 333) y José Sierra Álvarez («Introducción: la obra social de Le Play», en Campesinos y pescadores del Norte de España, Madrid, MAPA, 1990, 15 y 34).

${ }^{54}$ La metodología de Le Play es considerada por J. R. Pitts, que realiza una interpretación dualista de su pensamiento, la «invención de un antiempírico». J. R. PITTS, «Le Play, Frédéric», en D. L. Sills (dir.), Enciclopedia Internacional de Ciencias Sociales, Madrid, Aguilar, 1974, VI, 564. Gïde y Rist achacaron al método de Le Play «una fuerte dosis de dogmatismo» (C. GÏDE y C. RIST, Histoire des doctrines economiques, París, Recueil, 1913, 579, nota 2).

55 J. R. PitTs, «Le Play, Frédéric», en D. Sills (dir.), Enciclopedia Internacional de Ciencias Sociales, Madrid, Aguilar, 1974, VI, 564.

${ }^{56}$ El carácter ilustrativo del método inductivo leplaysiano ha sido señalado por Jean-René Tréanton: «Su método empírico no es inductivo, más bien ilustrativo: sus encuestas obreras le proveen de "viñetas", a las que adorna con exposiciones doctrinales, que van más allá de los materiales empíricos que él recopila» (J. R. TRÉANTON, «Faut-il exhumer Le Play? ou les héritiers abusifs», Revue Française de Sociologie, XXV [1984], 461).

${ }^{57}$ El método dentro del esquema intelectual leplaysiano, como señala Rafael Sierra, representa más un "argumento para convencer" que "un instrumento de demostración científica» (R. SIERRA ÁlVAREZ, «Introducción: la obra social de Le Play», en F. LE PlaY, Campesinos y pescadores del Norte de España, Madrid, MAPA, 1990, 33). El «análisis ideológico», del que habló Emile Durkheim para referirse a las investigaciones sociales encaminadas a confirmar nociones e ideas, en las que no deja de estar presente en una u otra forma la observación de los hechos pero ésta ocupa un lugar secundario e interviene a modo de ejemplo o prueba confirmatoria, resulta por ello una interpretación aplicable a la teoría social leplaysiana impregnada de rasgos doctrinarios y dogmáticos (E. DURKHEIM, Las reglas del método sociológico, Madrid, Ediciones Morata, 1978, 46-49). La interpretación de los esquemas teóricos de Comte y de Spencer como "metafísica positivista», que Durkheim realizó en la nota segunda del prólogo a la primera edición, es también aplicable a la sociología leplaysiana. La sociología durkheimiana constituye un proyecto científico de signo positivista más elaborado y refinado que el de los sociólogos positivistas decimonónicos, y concretamente del leplaysiano. Los proyectos intelectuales de Le Play y Durkheim presentan, no obstante, analogías tanto formales como intelectuales. Le Play estuvo vinculado en la práctica a la sociología con el poder institucionalizado durante la etapa del Segundo Imperio, mientras que Durkheim lo estuvo con la Tercera República. La desorganización social, la armonía social, la organización de la clase obrera mediante el patronazgo, del que habló Le Play, se transformaron en la anomía, cohesión e integración del cuerpo social por medio de organizaciones profesionales del discurso durkheimiano (M. DION, «Sociologie et idéologie dominante dans l'oeuvre de F. Le Play et Durkheim», La Pensée, núm. 158 [1971], 55-68; J. R. PITTS, «Le Play, Frédéric», en D. L. Sills [dir.], Enciclopedia Internacional de Ciencias Sociales, Madrid, Aguilar, 1974, VI, 562). 
La reforma social leplaysiana se enmarca en la quiebra de las mediaciones profesionales y territoriales históricamente constituidas y preexistentes entre individuo y mercado de trabajo y en la neta separación entre Estado y sociedad civil que instauraron los regímenes políticos liberales y las sociedades capitalistas. La disociación de lo público con lo privado y de lo político con lo económico introdujo una serie de desajustes en las sociedades humanas, que desembocaron en la emergencia de un espacio acotado en la intersección de lo económico con la política conocido por el ámbito de lo social, que aspira a reunir transversalmente las esferas implicadas en la gestión de las sociedades humanas y aborda desde una perspectiva teórica como práctica las soluciones a dar a los problemas, conflictos, etc., planteados en el ámbito de la «cuestión social» y nacidos de la disociación de esferas de la vida humana instauradas por las sociedades capitalistas ${ }^{58}$. La reforma social leplaysiana persigue reunificar esferas como la política, la economía y la moral, disociadas en las sociedades liberales, con el objetivo de alcanzar la armonía y estabilidad sociales que la «mano invisible» del mercado anunciaba pero no llegaba a instaurar en la práctica. Desde esta perspectiva, la reforma social leplaysiana se constituía en un significativo proyecto intelectual por construir una "economía social» ${ }^{59}$ y un liberalismo económico a partir del descubrimiento de las «virtudes del cristianismo en materia social» ${ }^{60}$.

El intento leplaysiano por despertar la conciencia moral del empresario y, en definitiva, por eliminar las desigualdades más sangrantes y acusadas del sistema capitalista estaba llamado al fracaso. Por un lado, perseguía personalizar las relaciones entre los agentes sociales dentro de un sistema económico cuyas bases fundamentales de constitución partían exactamente de la situación contraria articulada sobre la despersonalización de las relaciones sociales. Por otro, tras la experiencia de la Comuna de París de 1871, cualquier política pública en el ámbito social y económico, para ser aceptada, debía atender a los intereses tanto de empresarios como de trabajadores y, en este contexto, la propuesta leplaysiana de organización de la sociedad industrial, basada en los intereses del empresariado, no tenía posibilidad alguna de salir adelante.

La teoría leplaysiana acentuó la importancia de la familia dentro de la organización social, pero, al hacer derivar las estructuras familiares de los sistemas de herencia, confundió el efecto con la causa, que, por otro lado, se le escapó y no llegó a identificar. El pensador francés, en el trasfondo de un orden social anclado en un tiempo inmóvil y una estructura social inmutable,

58 La Revolución de 1848 constituyó la expresión de nuevos problemas, que desembocaron en la emergencia de lo social como un espacio de poder conformado por el entrecruzamiento de discursos, programas, estrategias y prácticas contrapuestos (J. DONZELOT, L'invention du social: essai sur le declin des pasions politiques, París, Fayard, 1984).

59 R. Sierra Álvarez, "Introducción: la obra social de Le Play», en F. LE Play, Campesinos y pescadores del Norte de España, Madrid, MAPA, 1990, 42-49.

${ }^{60} \mathrm{~J}$. DONZELOT, L'invention du social: essai sur le declin des pasions politiques, París, Fayard, 1984,45 . 
situó la familia troncal en la cima de una escala imaginaria de valores sociales y transformó aquélla en un mito más que en una forma histórica determinada de sucesión familiar ${ }^{61}$. Le Play dejó en un segundo plano las tensiones y conflictos familiares entrañados por las prácticas hereditarias de reparto desigual y, en cualquier caso, no llegó a comprender que el origen y razón de ser de la familia troncal responde a las necesidades concretas de producción/reproducción de las condiciones materiales de existencia en comunidades rurales de montaña, de las que la propiedad comunal y la conservación del patrimonio familiar constituyen sus principales manifestaciones ${ }^{62}$. Frédéric Le Play y, tras él, los miembros de su escuela sociológica mezclaron de forma confusa una antigua categoría económica (la proindivisión de los bienes familiares) con una categoría jurídica elaborada (la libertad de testar) en proceso de regresión histórica ${ }^{63}$. Casualmente, en 1882, año de la muerte de Le Play, Savina, la heredera de la familia pirenaica propietaria de la casa Melouga, presentada desde su descubrimiento en 1856 como modelo de familia troncal, vendió la casa y tierras familiares acuciada por las presiones familiares y seducida por el aumento de los precios de la tierra provocado por la creciente utilización de las agua termales de Cauterts ${ }^{64}$.

El pensamiento leplaysiano representa, dentro de la historia de las ciencias sociales, un avance indudable en cuanto al método científico, así como convierte en objeto de investigación el cambio y la movilidad sociales. Además, la estrategia investigadora de Le Play de proyectar contenidos científicos en la praxis político-social marcó un camino que, en lo sucesivo, será frecuentemente recorrido en las ciencias sociales. Los contenidos ético-espirituales y la recuperación de las instituciones sociales intermedias (familia, comunidades locales, propiedad comunal), que conformaron su propuesta de reforma social a partir de su discurso científico sobre la problemática de las condiciones de vida de la clase trabajadora, reaparecerán en gran parte de los proyectos reformistas ${ }^{65}$ pos-

${ }^{61}$ Cf. L. Assier-Andrieu, «Le Play et le famille-souche des Pyrénées: politique, juridisme et science sociale», Annales, núm. 3 (1984), 508, y J. R. Treanton, «Faut-il exhumer Le Play? ou les héritiers abusifs», Revue Française de Sociologie, XXV (1984), 458-483.

${ }_{62}$ Assier-Andrieu, con motivo de la revisión del pensamiento leplaysiano, da cuenta cómo un estudio sobre la comunidad rural pirenaica de Ossau, realizado sobre la base de una encuesta al conjunto del valle (F. BUTEL, La Vallée d'Ossau, Pau, 1894), repensó la misma realidad y aportó un esquema explicativo basado en las condiciones de producción y reproducción de la existencia material (L. Assier-Andrieu, «Le Play et le famille-souche des Pyrénées: politique, juridisme et science sociale», Annales, núm. 3 [1984], 506-507).

${ }^{63}$ H. Lefevre (coord.), «Structures familiales comparées», en G. Friedmann (ed.), Villes et campagnes, París, A. Colin, 1953, 329-330.

${ }_{64}$ F. Le Play, L'Organisation de la famille, Tours, A. Mame et Fils, 1895, 294-297.

${ }_{65}$ Asimismo, la influencia leplaysiana se extendió también al pensamiento social crítico. Esta corriente de pensamiento en versión anarquista construyó un modelo socialista esencialmente pluralista y descentralizado sobre la base de la confederación de las familias campesinas, los grupos de ayuda mutua, las comunidades locales, etc. Las construcciones teóricas de Joseph Proudhon, Piotr Kropotkin o Georges Sorel no son ajenas a las influencias teóricas de Bonald y Le Play. Cf. J. C. Mariategui, Siete ensayos de interpretación de la realidad peruana, Lima, Amauta, 1995, 67, nota 23, y R. NisBeT, Conservadurismo, Madrid, Alianza Editorial, 1995, 1). 
teriores surgidos en Europa dentro del ámbito de las ciencias sociales. Así, el camino recorrido por Le Play sirvió de punto de referencia en la creación intelectual de pensadores sociales católicos como el economista belga E. Lavelaye ${ }^{66}$ o, en nuestro ámbito intelectual más cercano, el sociólogo Severino Aznar.

\section{RECEPCIÓN DEL PENSAMIENTO LEPLAYSIANO EN ESPAÑA}

Las obras de Le Play tuvieron una reducida y tardía difusión en castellano, que contrasta con el interés manifestado por el pensador francés por España, especialmente por Cataluña y País Vasco. La edición de La Organización social y La Ley del Decálogo, realizada en 1895 por la editorial francesa Alfred Mame e Hijos, y la traducción de la antología de textos leplaysianos, recopilados y precedidos de una introducción a cargo de Auburtin, agota la lista de trabajos publicados en castellano ${ }^{67}$ tras la muerte de Le Play. En 1990, un siglo después, se publicaron diferentes monografías sobre comunidades campesinas y pescadoras del norte de España, redactadas o dirigidas por Le Play y publicadas en Les ouvriers des deux mondes $(1857)^{68}$. Le Play, no obstante, era un pensador social que fue ya conocido en vida por los círculos intelectuales y políticos españoles. Así, los contactos que Trueba mantuvo a través del Conde de Moriana ${ }^{69}$ con Le Play, el pensador social más importante de la escuela román-

${ }^{66}$ Emile LaVelaye (1828-1892) publicó numerosas obras, pero hay una que destaca sobre las demás: De la propriété et des ses formes primitives, París, Librerie Germer Balliére, 1874. En esta obra, el economista belga, influido por los programas de renovación social inspirados en principios cristianos, se apoyó en la propiedad comunal y en el derecho consuetudinario para formular una propuesta reformista de los problemas sociales que aquejaban a las democracias liberales europeas. Véase, en este sentido, J. M. a GARAYO URRUela, La propiedad comunal en pensamiento social agrario: perspectivas sociológicas, Bilbao, núm. 410 de la serie Colección Microfichas «Tesis doctorales» de la Universidad de Deusto, 1999, 93-104.

67 J. Sierra Álvarez, «Introducción: la obra social de Le Play», en F. LE Play, Campesinos y pescadores del Norte de España, Madrid, MAPA, 1990, 19, nota 15. El trabajo de Auburtin sobre Le Play apareció publicado en la colección "Ciencia y Acción. Estudios sociales», dirigida concretamente por Severino Aznar y con Saturnino Calleja como editor.

${ }^{68}$ F. LE PlaY, Campesinos y pescadores del Norte de España, Madrid, MAPA, 1990.

${ }^{69}$ A. de Trueba, Bosquejo de la organización social de Vizcaya, Bilbao, J. E. Delmas, impresor, 1870, 9-15. Ignacio Fernández de Henestrosa, Conde de Moriana, diplomático de ascendencia encartada (A. GonZÁleZ DE URQUiJO, "El Conde Moriana del Río. Estudio biográfico», Boletín de la Comisión de Monumentos Históricos y Artísticos, núm. 3 [1911], cuaderno 1, 37-42) y perfecto conocedor de las costumbres e instituciones de Bizkaia, puede considerarse un personaje clave en los acontecimientos que precedieron y siguieron a la elaboración del Bosquejo. Le Play le había nombrado miembro del Jurado Especial de la Exposición de 1867 en representación de España. A este personaje, aunque sin descartar la participación de Le Play en ello, le correspondió la iniciativa de dirigirse a la Diputación Foral de Vizcaya para recabar información sobre la organización social del territorio vizcaíno. El Conde de Moriana, en su carta de invitación, contribuyó, además, a prefigurar en cierto modo la orientación del informe al circunscribir sus contenidos a las costumbres, los fueros e instituciones que puedan considerarse ejemplos de armonía entre clases sociales y fuente de bienestar para el conjunto de la población (A. de TrUE- 
tica francesa en aquella época, contribuyeron a que la corriente romántica conservadora del País Vasco traspasase el ámbito de lo literario para adentrarse en el campo del ensayo y del pensamiento social ${ }^{70}$.

Antonio Manuel María de Trueba y de la Quintana (Montellano/Galdames, 1819-Bilbao, 1889) fue el principal representante del movimiento romántico surgido en el País Vasco tras el desenlace de la Primera Guerra Carlista en el ámbito literario, con la defensa del régimen foral y el ruralismo como elementos teóricos principales ${ }^{71}$. La obra en la que Trueba formuló de una manera completa y articulada su pensamiento social agrario consiste en el Bosquejo de la organización social de Vizcaya (1870). La redacción del Bosquejo por parte de Trueba responde en su origen a un encargo de la Diputación Foral en respuesta a la invitación recibida por ésta para presentar un informe sobre la organización económica, política y social del territorio vizcaíno en la Exposición Universal de $1867^{72}$, de la que Le Play, como ya se ha indicado anteriormente, fue Comisario General. Le Play entró, por tanto, en contacto con Trueba en el momento más álgido de su carrera política y proyección

BA, Bosquejo de la organización social de Vizcaya, Bilbao, J. E. Delmas, impresor, 1870, 11-13). Una vez redactada la memoria, el Conde de Moriana contribuyó a su difusión con la traducción del resumen publicado y, a su vez, ejerció de corresponsal entre la Société d'Économie Sociale y Le Play con A. de Trueba y la Diputación con el fin de recabar aclaraciones o informaciones más detalladas sobre el contenido de la memoria (A. de TRUEBA, Bosquejo de la organización social de Vizcaya, Bilbao, J. E. Delmas, impresor, 1870, 78 y ss.). El mencionado Conde asistió como invitado a las deliberaciones que, con la memoria como objeto de debate, mantuvo la Société d'Économie Sociale durante la sesión del 9 de febrero de 1868. La Diputación de Bizkaia premió la labor realizada por el Conde de Moriana a favor de los fueros e instituciones vizcaínos con la distinción de Padre de la Provincia (A. de TruebA, Bosquejo de la organización social de Vizcaya, Bilbao, J. E. Delmas, impresor, 1870, 6).

70 Le Play, de cualquier modo, conocía la realidad vasca pues había dirigido y participado en torno a 1856 en la elaboración de una monografía familiar sobre la familia pescadora en San Sebastián (F. LE PLAY, Campesinos y pescadores del Norte de España, Madrid, MAPA, 1990, 121169), que apareció publicada en el primer tomo de Les ouvriers des deux mondes (1857), y precisamente por ello no era ningún desconocido en el País Vasco. Así, la Diputación Foral de Bizkaia se refirió a él como una persona que "conoce a las provincias hermanas y las ama como si fuera uno de sus hijos» (A. de TRUEBA, Bosquejo de la organización social de Vizcaya, Bilbao, J. E. Delmas, impresor, 1870, 89).

71 J. JuAristi, El linaje de Aitor, Madrid, Ediciones Taurus, 1987, 31-33. Para un estudio más completo de Trueba, véase el trabajo de J. M.a GARAYO URruELA, "Clásicos del pensamiento social agrario en el País Vasco: Foronda, Trueba y Belausteguigoitia", Inguruak, núm. 25 (1999), 38-52.

72 La invitación fue girada en carta fechada el 26 de julio de 1867 por el Vicepresidente de la Comisión Regia en España de la Exposición de París, cargo ostentado por el Conde de Moriana. La Diputación Foral de Bizkaia, a pesar de las dificultades de tiempo entrañadas para la elaboración de la memoria solicitada, aceptó la invitación por carta de 3 de agosto de 1867 (A. de TRueBA, Bosquejo de la organización social de Vizcaya, Bilbao, J. E. Delmas, impresor, 1870, 1617). La redacción del informe se consideraba una inmejorable oportunidad publicitaria dentro de la polémica mantenida con el Gobierno central sobre la cuestión de los Fueros. La Diputación, en este contexto, acordó encargar la elaboración del informe a Antonio de Trueba, que realizó la tarea en poco más de un mes. 
pública. El encuentro de Trueba con Le Play contribuyó a que el primero diera cierta forma teórica al vago romanticismo popular surgido en torno al hecho político de los Fueros.

El Bosquejo constituye un ensayo histórico preferentemente descriptivo, pero no por ello carente de planteamientos teóricos e ideológicos ${ }^{73}$. El pensamiento político de la memoria puede resumirse en la siguiente tesis: la población vizcaína, asentada en un reducido territorio poco favorecido naturalmente para la producción agraria, disfruta de una relativa prosperidad por el efecto favorable de la posesión de las libertades contenidas en los Fueros ${ }^{74}$. El Bosquejo, en consonancia con los intereses más inmediatos de la institución promotora del informe, puede considerarse en cierto modo un alegato en pro de los Fueros. El pensamiento social del informe refleja una defensa a ultranza de la sociedad tradicional, particularmente de la organización familiar patriarcal y el fomento del amor y el apego a la región y país de origen, combinados de manera contradictoria con la transformación económica. El inmovilismo en los campos político-institucional y moral con el avance en lo económico se postulan por Trueba como una alternativa que pretendía aglutinar a las masas campesina y crear de este modo un contrapeso al creciente inconformismo social y venidera contestación política de la clase obrera de las zonas urbanas.

La memoria sirvió de base para que las instituciones y costumbres vascas recibieran una elogiosa cita en el informe realizado por el Jurado Especial de la Exposición y obtuvieran una mención específica en el concurso abierto para premiar los objetos o instituciones destinados a mejorar la condición física y moral de la población ${ }^{75}$. Como se puede comprobar por los apéndices, el propio Le Play, estimulado por la lectura de la memoria y por los conocimientos

${ }^{73} \mathrm{La}$ memoria consta de siete apartados. El primero describe las condiciones naturales en las que se desenvuelve la producción agraria y analiza el grado de adelanto experimentado por la agricultura en el territorio vizcaíno. El segundo repasa el estado de la industria, la beneficencia y la instrucción pública. El tercero estudia la organización social. El cuarto cuenta los orígenes de la sociedad vizcaína y examina el desarrollo histórico de la misma. El quinto expone la recopilación de las principales leyes contenidas en el código foral vizcaíno. El sexto se refiere al derecho de los vizcaínos a reunirse en junta general según la legislación consuetudinaria. El séptimo enumera las principales conclusiones del informe. Por la cortedad de tiempo que tuvo para la redacción del informe, Trueba fue consciente de abordar la temática mencionada de forma incompleta y desordenada. Por ello, el mismo escritor consideró la memoria unos «incompletos y desaliñados apuntes" (A. de TRUeBA, Bosquejo de la organización social de Vizcaya, Bilbao, J. E. Delmas, impresor, 1870, 76).

${ }^{74}$ A. de Trueba, Bosquejo de la organización social de Vizcaya, Bilbao, J. E. Delmas, impresor, $1870,19-20$.

75 A. de Trueba, Bosquejo de la organización social de Vizcaya, Bilbao, J. E. Delmas, impresor, 1870, 98-103. Un extracto en francés apareció publicado en el tomo II, correspondiente al año 1868, del Bulletin de la Société Internationale des Etudes Pratiques d'Économie Sociale. La memoria fue también objeto de debate y discusión en ciertos foros intelectuales de París. Así, por ejemplo, los miembros de la Société d'Économie Sociale trataron el tema en sesiones celebradas el 12 de enero y 9 de febrero de 1868 (A. de Trueba, Bosquejo de la organización social de Vizcaya, Bilbao, J. E. Delmas, impresor, 1870, 124-156). 
directos que tenía sobre el País Vasco, se dirigió a Trueba por carta de 21 de febrero de 1868 solicitando su colaboración con vistas a incluir un apartado dedicado a los usos, costumbres y leyes de Bizkaia en la cuarta edición de La Réforme Sociale ${ }^{76}$. Trueba, no sin antes manifestar sus dudas de poder satisfacer las expectativas abiertas, se comprometió a enviarle en los términos prefijados la colaboración solicitada, dándole libertad absoluta para usar o, en su caso, rechazar el trabajo enviado ${ }^{77}$. Le Play se sirvió de la colaboración de Trueba para incorporar en sus obras diversas referencias a la organización social del País Vasco ${ }^{78}$.

El Bosquejo refleja planteamientos y temática muy similares a los recogidos por Le Play. Instituciones tradicionales modélicas por su carácter armónico, estable y benefactor para el conjunto de la población, familia troncal, conservadurismo moral, liberalismo económico, etc., constituyen elementos teóricos comunes a ambos. El método leplaysiano de examinar las formas de trabajo y modos de vida de una familia que pudiera «servir de tipo para conocer a las demás» fue, asimismo, señalado por Trueba en el primer apartado de la memoria como un medio de exponer los adelantos experimentados por la agricultura y ganadería vizcaínas y el «bienestar relativo» alcanzado por el campesino vizcaíno $^{79}$. El intento realizado, en este sentido, por Trueba discurrió, en cualquier caso, por contenidos literarios sin llegar a alcanzar un mínimo rigor científico.

El Bosquejo no incluyó apenas datos cuantitativos concretos y, cuando esto se produce, algunos de ellos no son a veces sino ingenuas extrapolaciones de datos anticuados, caso, por ejemplo, de la estimación del aumento de la producción agraria, calculado sobre la base de multiplicar por tres la cuantía de las producciones dadas por Iturriza ${ }^{80}$. Todo ello obedece, sin duda, a la escasa preparación del escritor encartado en el campo de la erudición y la investigación históricas ${ }^{81}$. La descripción del mundo rural vizcaíno realizada por Trueba fue,

${ }^{76}$ A. de Trueba, Bosquejo de la organización social de Vizcaya, Bilbao, J. E. Delmas, impresor, 1870, 114-115.

77 A. de Trueba, Bosquejo de la organización social de Vizcaya, Bilbao, J. E. Delmas, impresor, 1870, 117-118.

${ }^{78}$ F. LE Play, L'organisation de la famille selon le vrai modéle signalé pour l'histoire de toutes les races et de toutes les temps, Tours, Alfred Mame et Fils, libraires-éditeurs (quatriéme edition), 1893, 22, 51 y 380; L'organisation du travail selon la coutume des ateliers et la loi du Décalogue, Tours, Alfred Mame et Fils (sixiéme edition), 1895, 41-44 y 96-97.

79 A. de Trueba, Bosquejo de la organización social de Vizcaya, Bilbao, J. E. Delmas, impresor, 1870, 22-23.

${ }^{80}$ A. de Trueba, Bosquejo de la organización social de Vizcaya, Bilbao, J. E. Delmas, impresor, 1870,22 , nota.

${ }_{81}$ M. Menéndez Pelayo, «Dos opúsculos inéditos de D. Rafael Floranes y D. Tomás Antonio Sánchez», en Obras completas. Estudios y discursos de crítica histórica y literaria, Santander, VI, 45; M. Unamuno, «Vizcaya. Aprovechamientos comunes; Lorra; Seguro mutuo para ganado, etc.», Revista General de Legislación y Jurisprudencia, LXXXVIII, 42 y ss., en J. Costa (dir.), Derecho consuetudinario y economía popular en España, Barcelona, Ed. Manuel Soler, obra reeditada por la Editorial Guara (Zaragoza, 1986, 53). 
sobre todo, el resultado del conocimiento directo poseído por el escritor sobre campesinos y paisajes vizcaínos, completado con la documentación histórica y las estadísticas oficiales de las que pudo disponer en función de su cargo de Cronista y Archivero en las Juntas Generales. Un examen crítico del informe permite, en cualquier caso, considerarlo un documento histórico, en el que se describe la sociedad vizcaína de la época ${ }^{82}$ o, al menos, la sociedad rural vizcaína de mediados del siglo XIX.

Los seguidores de Le Play en España no destacaron por su número ni tampoco por su actividad. El Conde de Moriana citado, Narciso Gay, Rafael Rodríguez Cepeda y pocos más pueden citarse entre sus seguidores españoles. El número de miembros españoles pertenecientes a las Unions de la Paix Sociale en torno a 1895, es decir, veintitrés años después de la constitución de las mismas, ascendía a veinticinco personas, entre las que se encontraban profesores, ingenieros, abogados, propietarios y comerciantes, la mayoría de ellos radicados en Cataluña y el País Vasco ${ }^{83}$. La influencia del pensador francés, aunque de forma tardía y en una etapa posterior a su muerte, quedó, a su vez, reflejada en la creación intelectual de algunos pensadores españoles, a los que se puede considerar entre los precursores de la sociología en España ${ }^{84}$. Aparte de la supuesta influencia ejercida sobre Andrés Posada ${ }^{85}$, el esquema intelectual leplaysiano reaparece de forma clara en la indagación intelectual de un pensador social católico como Severino Aznar.

Severino Aznar Embid (Tierga [Zaragoza], 1870-Madrid, 1959), catedrático de Sociología por la Universidad de Madrid $(1930)^{86}$, representa la persona-

82 A. Mañaricúa, Historiografía de Vizcaya (Desde Lope García de Salazar a Labayru), Bilbao, La Gran Enciclopedia Vasca, 1973, 372.

83 J. Sierra ÁlvareZ, «Introducción: la obra social de Le Play», en F. Le Play, Campesinos y pescadores del Norte de España, Madrid, MAPA, 1990, 20, nota 15.

${ }^{84} \mathrm{La}$ figura intelectual de Le Play atrajo la atención de pensadores españoles para fines del siglo XIX. El estudio de la figura intelectual de Le Play estuvo inicialmente vinculado a trabajos de carácter apologético (L. PIDAL MON, «Del método de observación en la ciencia social: Le Play su escuela", en Discursos de recepción y contestación leídos ante la Real Academia de Ciencias Morales y Políticas al dar posesión de sus plazas a los individuos de número de la misma, 1885-1888, Madrid, Tipografía de los Huérfanos, 1889, 461-526; M. Fraga IrIBarne, «La influencia de Le Play en la sociología española del siglo XIX», Revista Mexicana de Sociología, XVIII, núm. 3 [1956], 477-484). Para un análisis crítico del pensamiento leplaysiano, consúltense los trabajos siguientes: voz «Encuesta», en Enciclopedia Universal Ilustrada Europea-Americana, Madrid, Espasa Calpe, 1929, XIX, 1238-1249; H. CAPEL, Filosofía y ciencia en la geografia contemporánea, Barcelona, Barcanova, 1981, 297-300; J. CARO BAROJA, Los fundamentos del pensamiento antropológico moderno, Madrid, Consejo Superior de Investigaciones Científicas, 1985, 55-58; J. SIERRA ÁlVAREZ, "Introducción: la obra social de Le Play», en F. LE PlaY, Campesinos y pescadores del Norte de España, Madrid, MAPA, 1990, 11-49; J. GARCíA FERnÁNDEZ, "Sobre la sociedad rural de la España Atlántica a mediados del siglo XIX. Comentarios a la obra de F. Le Play», Agricultura y Sociedad, núm. 59 (1991), 271-281, y J. IGLESIAS DE USSEL, «Frédéric Le Play: mujer y familia en los inicios de la sociología», en M. a Angeles Durán (comp.), Mujeres y hombres en la formación de la teoría sociológica, Madrid, CIS, 1996, 113-147.

85 D. NúNEz RuIZ, La mentalidad positiva en España: desarrollo y crisis, Madrid, Túcar, $1975,238-239$ y 256.

${ }^{86}$ Para una reconstrucción biográfica de Severino Aznar puede consultarse a P. SANGRO y 
lidad intelectual más relevante dentro del pensamiento social católico español. Aznar promovió e impulsó la organización de las Semanas Sociales, celebradas por primera vez en 1906; la aparición de la Revista Internacional de Sociología (1943) y la constitución del Instituto Balmes de Sociología (1944), convertidos todos ellos durante la primera mitad del siglo XX en los vehículos de expresión y difusión intelectual de las corrientes reformistas de inspiración social católica en España.

Severino Aznar tomó como punto de partida de indagación teórica el pensamiento social católico formulado en las encíclicas Rerum Novarum (1891), de León XIII, y Quadragesimo Anno (1931), de Pío IX ${ }^{87}$. En las encíclicas papales mencionadas, Aznar creyó detectar una serie de ideas-fuerza que era preciso estimular su inserción en la conciencia individual y, a partir de ahí, en las costumbres, las leyes e instituciones, en cuanto de las mismas se desprendía un programa de reformas sociales que combatían la expansión de los movimientos sociales revolucionarios.

En el pensamiento social de Aznar, el lector no encontrará disquisiciones teóricas sobre los fundamentos últimos de la vida y el orden sociales. Sus preocupaciones intelectuales estuvieron centradas en un conocimiento preciso de la realidad, lo que le empujó a un perfeccionamiento en las técnicas de investigación social ${ }^{88}$. El interés investigador de Aznar discurrió preferentemente por los temas demográficos o por problemas tratados desde una perspectiva demográfica $^{89}$. Sus investigaciones sociales estuvieron todas ellas animadas por el objetivo práctico de diseñar un programa de reformas sociales en cuanto vía de solución de los problemas obreros y campesinos, ejes de la cuestión social.

Ros de Olano (La vida de un luchador, Madrid, 1952). En cuanto a análisis de su pensamiento social, resulta de interés la consulta de E. GÓmez Arboleya («Sociología en España», Revista de Estudios Políticos, núm. 18 [1958], 47-83), J. L. ItURRATe («Sociología en España. Notas para su historia», en J. Cazeneuve [dir.], La Sociología, Bilbao, Mensajero, 1975, 576-577) y E. SEvilla GuZMÁn («Sobre el pensamiento social agrario en España», en H. NEWbY y E. SEVILla GuZMÁn, Introducción a la Sociología rural, Madrid, Alianza Editorial, 1983).

${ }^{87}$ Aznar expuso estas ideas en el discurso leído en la Real Academia de Ciencias Morales y Políticas con motivo del L y X aniversario, respectivamente, de las encíclicas papales Rerum Novarum y Quadragesimo Anno (Las encíclicas "Rerum Novarum" y Quadragesimo Anno". Precedentes y repercusiones en España, Madrid, 1941). Este discurso, acompañado de otro trabajo de contenido similar titulado "Algunas orientaciones sociales de Pío XI» (1933), está incluido en la recopilación de obras del autor titulada Estudios religioso-sociales, Madrid, Instituto de Estudios Políticos, 1949, 119-182 y 47-67.

${ }^{88}$ Gómez Arboleya se refirió a este rasgo del pensamiento social de Aznar en los siguientes términos: "Aznar es católico, y por ello no se hizo problema de la sociedad en cuanto tal, sino se planteó problemas respecto a una sociedad (...) Aznar no se preocupa de los últimos fundamentos del orden social, los da por supuesto: examina la sociedad tal como es. Sienta plaza de sociólogo positivo» (E. Gómez ARboleya, "Sociología en España», Revista de Estudios Políticos, núm. 98 [1958], 57).

${ }^{89}$ S. Aznar fue el promotor de los estudios de demografía llevados a cabo por el Instituto Balmes de Sociología (S. Aznar [dir.], Estudios demográficos, Madrid, CSIC, 1962). Véase, en este sentido, J. L. ITURRATE, «Sociología en España. Notas para su historia», en J. Cazeneuve (dir.), La Sociología, Bilbao, Mensajero, 1975, 576-577. 
Dentro de la bibliografía intelectual de Aznar, merecen una mención especial dos libros: La abolición del asalariado (Madrid, 1921) y Despoblación y Colonización (Barcelona, Labor, 1930). Ambos estudios son complementarios uno de otro, pues mientras el primero aborda el problema social en la industria y en el comercio, el segundo lo hace en el campo y medio rural.

El trabajo La abolición del asalariado contiene el discurso leído el 13 de febrero de 1921 por S. Aznar en el acto de recepción como académico de número en la Real Academia de Ciencias Morales y Politicas. Aznar propuso como solución al problema social en la industria y en el comercio un programa de reformas basado en el aumento del número de propietarios industriales, la participación en los beneficios, etc., con vistas a llegar a una etapa en la que el capital quedase subordinado al trabajo y a formas de producción corporativa ${ }^{90}$.

El libro Despoblación y Colonización presenta dos partes claramente diferenciadas. La primera parte, dedicada al análisis de la despoblación, se desenvuelve en un estudio de los factores intervinientes en la inmigración rural de acuerdo con las técnicas propias de la ciencia demográfica. Aznar caracterizó el éxodo rural como el resultado de la concurrencia de múltiples condiciones y causas, que agrupó en las siguientes categorías: causas físicas, causas biológico-humanas (reducción de la natalidad y alta mortalidad, por ejemplo), causas jurídico-legales (derecho sucesorio y grado de concentración de la tierra, entre otras), causas económicas (salarios más altos y mejores condiciones de vida en la ciudad respecto al campo en cuanto factores más importantes) y causas sociales (baja consideración de la profesión agraria y reducción del espacio cultivable por la utilización del mismo para uso recreativo como la cría del toro de lidia y los cotos de caza, etc. $)^{91}$.

La solución al éxodo rural y campesino, analizado desde una perspectiva múltiple, radicaba, según Aznar, en la colonización. Al adentrarse en esta parte del libro, Aznar abandona el campo científico de análisis y se adentra en el ámbito de la filosofía social. Con el pensamiento social católico de trasfondo, Aznar concretó los objetivos finales de su programa de reforma agraria basada en la colonización a la reducción del trabajo asalariado, a la extensión masiva de la propiedad privada ${ }^{92}$, a la constitución de una democracia rural sustentada

90 Dentro del régimen corporativo, Aznar, como el resto de pensadores católico-sociales, incluía la cooperativa de producción, el accionariado obrero, el contrato de propiedad, comunidades de trabajo basadas en la cogestión y las explotaciones familiares agrarias. Véase, en este sentido, la contestación de Aznar al discurso leído por Joaquín Azpiazu (Las directrices sociales de la Iglesia Católica, Madrid, Talleres Tipográficos de E. Sánchez, 1950, 31).

${ }_{91}$ Aznar desarrolló este esquema de investigación en Despoblación y Colonización, Barcelona, Labor, 1930, 17-82.

92 La difusión de la propiedad constituye el elemento central de la reforma demócrata-cristiana de la sociedad propuesta por Severino Aznar, para quien «con la difusión de la propiedad agraria, el ladrón de la propiedad se convierte en Guardia Civil, el revolucionario en su adversario más impecable y tenaz» (S. AZNAR, «Hacia la difusión de la propiedad rural [1937]», en Estudios políticos, Madrid, Instituto de Estudios Políticos, 1949, 42). La difusión de la propiedad como el conjunto de su propuesta reformista respondía fundamentalmente a la preocupación por contrarrestar el avance de las corrientes sociales revolucionarias. 
en una amplia base integrada por clases medias y, en definitiva, al bienestar general y a la estabilidad política ${ }^{93}$.

La reforma agraria propuesta por Aznar pretendió crear patrimonios agrarios cuya explotación, mediante una buena técnica agraria, absorbiese la fuerza laboral y cubriese las necesidades de las familias que la trabajasen, garantizándose de este modo la estabilidad en la tierra de las mismas ${ }^{94}$. Aznar postulaba un nuevo régimen de tenencia, "la propiedad socializada de la familia»" mediante el cual la tierra quedase asignada de forma permanente a las explotaciones agrarias familiares y a sus herederos. Según este nuevo régimen agrario, las tierras de las explotaciones agrarias familiares pasaban a conceptuarse jurídicamente como patrimonios inalienables, inembargables e indivisibles ${ }^{96}$.

En armonía con la demanda de tierra solicitada por colonos en posesión de una adecuada y acreditada capacitación agraria, Aznar propuso la articulación de una serie de medidas entre las que se incluían la concesión de tierras de propiedad estatal y municipal bajo la fórmula del arrendamiento o censo, la concesión de parcelas cultivables en terrenos de propiedad municipal y la expropiación en un primer momento de los latifundios mal explotados y, si llegase el caso y así lo requiriese el bien común, de latifundios bien explotados ${ }^{97}$.

La reforma agraria diseñada por Severino Aznar incluía, por tanto, la propiedad comunal, a la que se refería con el apelativo de "latifundio colectivo" ${ }^{98}$. El plan de Aznar para este tipo de programa consistía en la conservación patrimonial de este tipo de propiedades, pero con la eliminación de los elementos antieconómicos y antisociales ${ }^{99}$, que rodeaban su explotación y gestión, por medio de la intensificación productiva (instalación de riego en las tierras arables, repoblación forestal y mejora de pastos de los terrenos baldíos y montañosos) y mediante la concesión de parcelas a las familias de menores recursos como jornaleros y pequeños propietarios ${ }^{100}$. En el fondo, Severino Aznar veía

93 S. AzNAR, Despoblación y Colonización, Barcelona, Labor, 1930, 8.

94 S. Aznar, Despoblación y Colonización, Barcelona, Labor, 1930, 198-199.

95 La colonización agraria propuesta por S. Aznar se canalizaba a través de la constitución de patrimonios familiares de las características siguientes: «... a) Ser propiedad socializada de la familia, no del individuo; b) Ser pequeña propiedad; c) Ser suficiente para dar estabilidad a la familia en la tierra; d) Que no perjudique a la sociedad y, en general, que permita el cultivo según una buena técnica agraria” (S. AZNAR, Despoblación y Colonización, Barcelona, Labor, 1930, 198).

96 S. Aznar, Despoblación y Colonización, Barcelona, Labor, 1930, 185.

97 S. AZnar, Despoblación y Colonización, Barcelona, Labor, 1930, 29-31.

98 S. AZNAR, «La propiedad comunal» (1917), en Estudios económico-sociales, Madrid, Instituto de Estudios Políticos, 1946, 152.

99 Aznar señaló en este sentido: «... no toleréis su enajenación ni su intrusión, y procurad que sea más productiva y mejor utilizada» (S. AZNAR, "La propiedad comunal» [1917], en Estudios económico-sociales, Madrid, Instituto de Estudios Políticos, 1946, 156). Véase respecto a este mismo asunto, además, el capítulo noveno de su trabajo La acción social agraria en Navarra. Algunas reflexiones sobre su porvenir y futuro (Pamplona, Imprenta de "La Acción Social», 1916, 101-112), en el que aplicó su propuesta de reforma de la propiedad comunal al caso concreto de las corralizas de Tudela.

100 S. AZNAR, «La propiedad comunal» (1917), en Estudios económico-sociales, Madrid, Instituto de Estudios Políticos, 1946, 152-156. 
en la propiedad comunal una especie de colchón que podía servir para amortiguar las tensiones y conflictos sociales surgidos en pueblos compuestos mayoritariamente por jornaleros agrícolas.

La colonización, según el plan de Aznar, representaba una empresa cuya ejecución requería importantes recursos económicos, particularmente por asociarla con la dotación de sistemas de riego a tierras de secano. Aznar, en este contexto, concibió la colonización como el resultado de la acción privada, por lo que defendía la movilización en este sentido de las organizaciones y agentes sociales agrarios del mundo rural. De cualquier modo, reconocía que, dada la envergadura de la empresa, era necesario algún tipo de intervención del Estado aun en "circunstancias normales y de estática social», convirtiéndose en «insustituible y urgente» en los "momentos de crisis para la institución de la propiedad agraria ${ }^{101}$.

Los ingredientes teóricos analizados en el pensamiento social leplaysiano reaparecen en el esquema intelectual de Aznar: teoría social basada en la doctrina católica, positivismo metodológico y reformismo social de índole moral articulado en torno a la familia y a la difusión de la propiedad corporativa. La reflexión intelectual de Aznar se desenvolvió al margen de las corrientes teóricas imperantes en la sociología mundial de la época ${ }^{102}$. Las fuentes de inspiración teórica de Aznar se encontraban, por el contrario, en la doctrina social católica y en los teóricos sociales precursores del catolicismo social ${ }^{103}$. Aznar, en este contexto, se valió de las aportaciones de Le Play para apoyar teóricamente la principal base de su propuesta reformista: la "propiedad socializada de la familia» ${ }^{104}$.

101 S. AZNAR, Despoblación y Colonización, Barcelona, Labor, 1930, 133.

102 En el contexto de la polémica mantenida con A. Perpiñá sobre la figura de Aznar, en la que este último le criticaba al primero por considerarle un «ilustre precursor» de la sociología española, "un publicista», "un misionero social» y no incluirle en la nómina de sociólogos (A. Perpiñ́, Nueva y vieja sociología, Madrid, Real Academia de Ciencias Morales y Políticas, 1967, 18), Amando de Miguel señaló que a Severino Aznar «le faltó para ser un sociólogo el grupo de referencia de la sociología mundial, que parece desconocer» (A. DE MiguEL, Sociología o subversión, Barcelona, Plaza y Janés, 1972, 35). La participación de Aznar en foros y congresos de ciencias sociales y sociología de ámbito internacional y las frecuentes salidas al extranjero, más que desconocimiento, indican una arriesgada y pensada apuesta intelectual por convertir la doctrina social católica en fuente teórica de sus investigaciones empíricas.

${ }^{103}$ El análisis del contenido social de las encíclicas papales Rerum Novarum y Quadragesimo Anno y de sus repercusiones en España realizado por Aznar estuvo acompañado de un estudio de los precedentes que, en su opinión, las mismas habían tenido entre pensadores españoles. Entre éstos, incluyó a Balmes, Donoso Cortés, Cánovas del Castillo y Mella (Estudios religioso-sociales, Madrid, Instituto de Estudios Políticos, 1949, 119-182). Las fuentes de inspiración teórica de Aznar procedían de los pensadores sociales que habían contribuido a conformar el movimiento social católico. Según sus palabras, los más importantes, entre otros, eran «Ketteler, Vogelsand, Manning, Perrin, Le Play, Decurtins, Hitze, Mun, Toniolo, Balmes, Donoso Cortés, concepción Arenal, etc.» (S. AZnAR, Problemas sociales de actualidad, Barcelona, 1914, 205).

104 Aznar, imbuido de un ingenuo antimarxismo, pretendió combatir la expansión del comunismo por medio de la difusión de la propiedad bajo fórmulas corporativas y familiares. La exposición de esta idea estuvo siempre vinculada con citas a la obra leplaysiana (La abolición del asalariado, Madrid, 1921, 23-24; Despoblación y Colonización, Barcelona, 1930, 155, 178 y 186). 
En fin, el balance de la obra de Aznar resulta, en este sentido, parejo a la de Le Play: avance en la investigación empírica, esterilizado y lastrado teóricamente $^{105}$ por su fuerte conexión con elementos ideológicos, provenientes en ambos casos del catolicismo social. En cualquier caso, el papel concedido por Le Play al grupo doméstico en cuanto elemento ordenador y regulador de valores sociales abrió una línea de indagación teórica que persiste hoy en día y enlaza con la perspectiva culturalista que actualmente desarrolla la corriente de las ciencias sociales francesas, encabezada por Emmanuel Todd ${ }^{106}$, en el análisis de la evolución y modernización ideológica, religiosa y política de Europa Occidental a partir de las relaciones entre diversidad antropológica en cuanto a sistemas familiares y a tradiciones religiosas e ideologías sociales y comportamientos políticos.

\section{BIBLIOGRAFÍA}

ARnault, F. (1984): «Frédéric Le Play, de la métallurgie à la science sociale», Revue Française de Sociologie, XXV, 437-457.

Assieur-Andrieu, L. (1984): «Le Play et la famille-souche des Pyrénées: politique, juridisme et science sociale», Annales. Economies, Sociétés, Civilisations, núm. 3, 495-512.

Auburtin, F. (comp.): Federico Le Play según él mismo. Vida-Método-Doctrina. Datos y trozos escogidos, traducción de C. Gallardo, Madrid, Saturnino Calleja, S.A.

Aznar Embid, S. (1914): Problemas sociales de actualidad, Barcelona, Acción Social Popular.

- (1916): La acción social agraria en Navarra. Algunas reflexiones sobre su porvenir y futuro, Pamplona, Imprenta de «La Acción Social».

- (1921): La abolición del asalariado, Madrid, Sobrinos de la Sucesora de M. Minuesa de los Ríos.

- (1930): Despoblación y Colonización, Barcelona, Labor.

- (1941): Las encíclicas "Rerum Novarum» y "Quadragesimo Anno". Precedentes y repercusiones en España, Madrid.

- (1946): Estudios económico-sociales, Madrid, Instituto de Estudios Políticos.

- (1949a): Estudios religioso-sociales, Madrid, Instituto de Estudios Políticos.

- (1949b): Estudios politicos, Madrid, Instituto de Estudios Políticos.

- (dir.) (1962): Estudios demográficos, Madrid, CSIC.

Bonald, L. de (1840): Demonstration Philosophique du Principe Constitutif de la Société, París, Librarie d'Adrien Le Clere et $C^{\text {ie }}$.

BoudON, R. (1972): «An introduction to Lazarsfeld's philosophical papers», en P. S. LAzARSFELD, Qualitative Analysis, Historial and Critical Essays, Boston, 410-427.

105 A. de Miguel, Sociología o subversión, Barcelona, Plaza y Janés, 1972, 35; E. Sevilla GUZMÁN, «Sobre el pensamiento social agrario en España», en H. NEWBY y E. SEVILLA GuZMÁN, Introducción a la sociología rural, Madrid, Alianza Editorial, 1983, 201.

106 E. TODD, La troisiéme planéte: structures familiales et systémes idéologiques, París, Seuil, 1983; La nouvelle France, París, Seuil, 1988; L’invention de l'Europe, París, Seuil, 1990. Para un comentario crítico de la obra de Todd, léase a H. MEndras, «E. Tood, La troisiéme planéte: structures familiales et systémes idéologiques», Revue Française de Sociologie, XXV (1984), 484488, y a H. DÉCHAUX, "Structures de parenté et société paysannes: deux points de vue et des suggestions pour une sociologie de la parenté dans les sociétés urbaines», Archives Européennes de Sociologie, XXXII (1991), 153-171. 
BRUNHES, J. (1948): Geografia humana, Barcelona, Editorial Juventud.

BUTTIMER, A. (1971): Sociedad y medio en la tradición geográfica francesa, Barcelona, Oikos-Tau.

CAPEL, H. (1981): Filosofía y ciencia en la Geografía contemporánea, Barcelona, Barcanova Editorial, S.A.

Cazeneuve, J. (dir.) (1975): La Sociología, Bilbao, Mensajero.

Cheysson, M. E. (1895): "La famille-souche du Lavedan, de 1869 a 1883», en F. Le Play, L'Organisation de la famille, Tours, A. Mame et Fils, 212-300.

Demolins, E. (1882): «Le Play et son oeuvre de réforme sociale», La Réforme Sociale, núm. 1, 409-423.

Dion, M. (1971): «Sociologie et ideologie dominante dans l'oeuvre de F. Le Play et Durkheim», La Pensée, núm. 158, 55-68.

DéCHAuX, J. H. (1991): «Structures de parenté et société paysannes: deux points de vue et des suggestions pour une sociologie de la parenté dans les sociétés urbaines», Archives Européennes de Sociologie, XXXII, 153-171.

Ferraroti, F. (1976): Hombres y máquinas en la sociedad industrial, Barcelona, Labor.

Fraga IrIbarne, M. (1956): «La influencia de Le Play en la sociología española del siglo XIX», Revista Mexicana de Sociología, XVIII, núm. 3, 477-484.

Fretcher, R. (1970): «Frédéric Le Play», en T. Raison (ed.), Los padres fundadores de la ciencia social, Barcelona, Anagrama, 51-58.

Fourcy, L. de (1883): «Le Play. L’ingénieur des mines», La Réforme Sociale, núm. 1, 29-44.

Garayo Urruela, J. M.a (1999): La propiedad comunal en pensamiento social agrario: perspectivas sociológicas, Bilbao, núm. 410 de la serie Colección Microfichas «Tesis doctorales» de la Universidad de Deusto.

- (1999): «Clásicos del pensamiento social agrario en el País Vasco: Foronda, Trueba y Belausteguigoitia», Inguruak, núm. 25, 19-65.

García FernándeZ, J. (1991): «Sobre la sociedad rural de la España Atlántica a mediados del siglo XIX. Comentarios a la obra de F. Le Play», Agricultura y Sociedad, núm. 59, 271-280.

GİDE, C., y RIST C. (1913): Histoire des doctrines economiques depuis les physiocrates jusqu'a nos jours, París, Librairie de la Société du Recueil Sirey.

Gómez Arboleya, E. (1958): «Sociología en España», Revista de Estudios Políticos, núm. 98, 4783.

GonzÁlez de Urquijo, A. (1911): «El Conde Moriana del Río. Estudio biográfico», Boletín de la Comisión de Monumentos Históricos y Artísticos, núm. 3, cuaderno 1, 37-42.

JUARISTI, J. (1987): El linaje de Aitor, Madrid, Ediciones Taurus.

IgLeSIAS DE UsSel, J. (1996): "Frédéric Le Play: mujer y familia en los inicios de la sociología», en M. a Ángeles Durán (comp.), Mujeres y hombres en la formación de la teoría sociológica, Madrid, CIS, 113-147.

Kalaora, B., y SaVoye, A.: (1983): "Frédéric Le Play, un sociologie engagé», postfacio a F. Le Play (dir.), Ouvriers des deux mondes: etude publiées par le Société d'Économie Sociale a partir de 1856, Thomery, A l'Enseigne de l'Arbre verdoyant editeur, 320- 334.

- (1984): Forêt et Sociologie. Les forestiers de l'Ecole de Le Play, defenseurs des populations de montagne 1860-1913, París, INRA.

LAVELAYE, E. (1874): De la propriété et des ses formes primitives, París, Librerie Germer Balliére.

Lazarsfeld, D. (1970): «Le Play et sa methode d'observation», en Philosophie des sciences sociales, París, Gallimard, 129-162.

LE Play, F. (1855): Les ouvriers européens. Etudes sur le travaux, la vie domestique et la condition morale des populations ouvriéres de l'Europe, precedées d'un exposé de le methode d'observation, París.

- (dir.) (1857): Le ouvriers des deux mondes. Etudes sur les travaux la vie domestique et la condition morale des populations ouvriéres des diverses contrées et sur les rapports qui les unissent aux autres clases, París, Société Internationale d'Etudes Pratiques d'Économie Sociale, 5 vols.

- (1884 y 1895): L'Organisation de la famille, selon le vrai modèle signalé par l'histoire de toutes les races et de tous les temps, Tours, Mame et Fils. 
LE PLAY, F. (1887): La réforme sociale en France deduite de l'observation comparée des peuples européens, Tours, Alfred Mame et Fils (7. a edición).

- (1888 y 1893): L'organisation du travail, selon la coutume des ateliers et la loi du Décalogue, Tours, Alfred Mame et Fils.

- (1881): La constitution essentielle de l'humanité. Exposé des principes et des coutumes qui créent la prosperité ou la soufrance des nations, Tours, A. Mame.

- (1883): Les ouvriers des deux mondes. Etudes publiés par la Société d'Economie Sociale á partir de 1856 sous le direction de Frédéric Le Play, Postface par Bernard Kalaora et Antoine Savoye, Thomery, A l'enseigne de l'arbre verdoyant editeur.

- (1890): Campesinos y pescadores del Norte de España, Madrid, MAPA.

MAISTRE, J. de (1858): Essai sur le principe générateur des Constitutions Politiques, Lyon, J. B. Pelagand et Cie.

Mañaricua, A. (1973): Historiografía de Vizcaya (Desde Lope García de Salazar a Labayru), Bilbao, La Gran Enciclopedia Vasca.

Mariategui, J. C: Siete ensayos de interpretación de la realidad peruana, Barcelona, Crítica, 1976, y Lima, Editorial Amauta, 1995 (sexagésimo-segunda edición).

Mendras, H. (1984): «E. Tood, La troisiéme planéte: structures familiales et systémes idéologiques», Revue Française de Sociologie, XXV, 484-488.

Menéndez Pelayo, M. (1961): «Dos opúsculos inéditos de D. Rafael Floranes y D. Tomás Antonio Sánchez», en Obras completas. Estudios y discursos de crítica histórica y literaria, Santander, VI, 41-82.

Miguel, A. de (1972): Sociología o subversión, Barcelona, Plaza y Janés.

NúNEzZ RuIZ, D. (1975): La mentalidad positiva en España: desarrollo y crisis, Madrid, Túcar.

Newby, N., y Sevilla GuZmán, E. (1983): Introducción a la Sociología rural, Madrid, Alianza Editorial.

PerpiñÁ, A. (1967): Nueva y vieja sociología, Madrid, Real Academia de Ciencias Morales y Políticas.

Perroux, F. (1964): Industrie et création collective. I: Saint-simonisme du XXe siècle et création collective, París, PUF.

PITTS, J. R. (1974): «Le Play, Frédéric», en D. L. Sills (dir.), Enciclopedia Internacional de Ciencias Sociales, Madrid, Aguilar, VI, 561-566.

Savoye, A. (1981): «Les continuateurs de Le Play au tournant de siécle», Revue Française de Sociologie, XXIIC, 315-344.

SANGRO y Ros De Olano, P. (1952): La vida de un luchador, Madrid.

Sierra Álvarez, J. (1990): «Introducción: la obra social de Le Play», en F. Le Play, Campesinos y pescadores del Norte de España, Madrid, MAPA, 11-49.

TODD, E. (1983): La troisiéme planéte: structures familiales et systémes idéologiques, París, Seuil.

- (1988): La nouvelle France, París, Seuil.

- (1990): L'invention de l'Europe, París, Seuil.

Treanton, J. R. (1984): «Faut-il exhumer Le Play? ou les héritiers abusifs», en Revue Française de Sociologie, XXV, 458-483.

Trueba, A. de (1870): Bosquejo de la organización social de Vizcaya, Bilbao, J. E. Delmas, impresor.

UnAmuno, M. (1896, 1902): «Vizcaya. Aprovechamientos comunes; Lorra; Seguro mutuo para ganado, etc.», Revista General de Legislación y Jurisprudencia, LXXXVIII, 42 y ss., en J. Costa (dir.), Derecho consuetudinario y economía popular en España, Barcelona, Ed. Manuel Soler, 35-66, obra reeditada por la Editorial Guara (Zaragoza, 1986). 


\section{ABSTRACT}

This article is an introduction to the social theory drawn up by Frédéric Le Play, who belonged to the classical group of social thought and is considered to be one of the founders of contemporary social sciences. 